http://dx.doi.org/10.18232/alhe.1030

Artículos

\title{
El tráfico comercial marítimo durante la invasión británica al Río de la Plata (1806-1807)
}

\section{Commercial maritime traffic during the British invasion of the Rio de la Plata (1806-1807)}

\author{
Mariano M. Schlez ${ }^{1}$ * DD 0000-0002-9095-6449 \\ ${ }^{1}$ Consejo Nacional de Investigaciones Científicas y Tecnológicas, Buenos Aires, Argentina. \\ *Correspondencia: mmschlez@criba.edu.ar
}

Resumen. El artículo tiene por objetivo describir, ponderar y analizar el tráfico comercial de buques de ultramar en el Río de la Plata durante la invasión británica (1806-1807), atendiendo particularmente a su origen, destino y pabellón. A partir de un balance historiográfico que justifica el planteamiento de la investigación, se propone una triangulación de fuentes seriales, publicaciones periódicas y documentación cualitativa, tanto británicas como españolas, que permitan superar las dificultades presentadas para el análisis de la cuestión. Concluimos que la invasión británica interrumpió el tráfico comercial entre España y el Río de la Plata, reorientando el flujo hacia los mercados británicos y extranjeros, asestando un golpe mortal al monopolio español y abriendo una etapa específica que llamamos comercio directo por invasión.

Palabras clave: historia del comercio internacional; tráfico marítimo; monopolio español; imperialismo.

Abstract. The article aims to describe, weigh and analyze the commercial traffic of overseas vessels in the Río de la Plata during the British invasion (1806-1807), paying particular attention to its origin, destination and flag. From a historiographic balance, that justifies the approach of the investigation, a triangulation of serial

CÓMO CITAR: Schlez, M. M. (2020). El tráfico comercial marítimo durante la invasión británica al Río de la Plata (1806-1807). América Latina en la Historia Económica, 27(1), e1030. DOI: 10.18232/alhe.1030

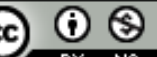

Esta obra está protegida bajo una Licencia Creative Commons Atribución-NoComercial 4.0 Internacional
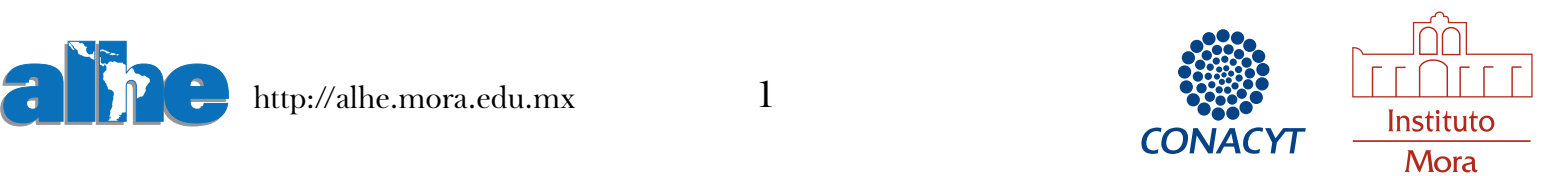
sources, periodical publications and qualitative documentation, both British and Spanish, is proposed, which allow overcoming the difficulties presented for the analysis of the question. We conclude that the British invasion interrupted the commercial traffic between Spain and the Rio de la Plata, reorienting the flow to the British and foreign markets, dealing a mortal blow to the Spanish monopoly and opening a specific stage that we call direct trade by invasion.

Key words: International Trade History; maritime traffic; Spanish monopoly; imperialism.

JEL: F54, N46, N76, N96.

Recibido: 23 de octubre de 2018.

Aceptado: 6 de diciembre de 2018.

Publicado: 10 de octubre de 2019.

Organismos patrocinadores: El Consejo Nacional de Investigaciones Científicas y Técnicas, Argentina; Universidad de Londres. Agradecimientos: a Hernán A. Silva y a Catherine Davies.

\section{INTRODUCCIÓN}

La destrucción del monopolio comercial español, como parte de los procesos independentistas revolucionarios de las primeras décadas del siglo XIX, constituye un elemento fundacional de las construcciones ideológicas nacionalistas desde los orígenes de las historiografías en América Latina. En el caso argentino, Esteban Echeverría (1951) destacó las virtudes de la "libertad de comercio" inaugurada por la Revolución de Mayo y sus beneficios para el desarrollo agrario, particularmente la valorización de las producciones bonaerenses gracias "a la concurrencia del extranjero en demanda de esos frutos, y al aprecio y estimación que de ellos hace” (p. 214). También Bartolomé Mitre (1940-1941) le otorgó un lugar preponderante al comercio, caracterizando al puerto de Buenos Aires como un espacio naturalmente predispuesto para un desarrollo mercantil, pero que era impedido por un sistema colonial monopólico que obstruía esta potencia, reflejado en una exclusión de la concurrencia y una supresión de la navegación. Por su parte, Vicente Fidel López (1964) señaló el esfuerzo español por "alejar el comercio marítimo" y "el conato con que naciones marítimas le disputaron a España el comercio y las entradas del Río de la Plata” (pp. 11-13). Luego de ellos, Ricardo Levene (1962) desarrolló estos planteamientos, otorgándole una "función revolucionaria" al puerto de Buenos Aires.

Frente a estas primeras hipótesis, un conjunto de investigaciones comenzó a mostrar que, en lugar de un final abrupto - causado por las independencias- el control del comercio español sobre sus colonias sufrió una lenta erosión que permitió el progresivo establecimiento de vínculos comerciales entre puertos extranjeros y las colonias españolas americanas. En este sentido, aunque el contrabando fue siempre un elemento de peso, se probó que vínculos legalmente establecidos, aunque limitados por la corona española, sirvieron como plataforma para nuevos desarrollos del tráfico con puertos extranjeros (Fisher, 2011; Segreti, 1987; Walker, 1979).

Para el caso del Río de la Plata, el comercio con puertos no españoles se manifiestó desde los orígenes de su navegación, a fines del siglo XVI, autorizado por medio de licencias específicas. Es notorio su crecimiento para la segunda mitad del siglo xvII, mediante el contrabando, funda- 
mentalmente holandés (Moutoukias, 1988), y a principios del xvIII, con el tráfico legal (e ilegal), auspiciado por los asientos de esclavos, otorgado primero a los franceses y luego a los ingleses, a los que se sumaba el contrabando británico desde Colonia de Sacramento (Jumar, 2002, 2012).

Pasada la segunda mitad del siglo XviII, aunque la navegación española recuperó territorio, en el marco de una continuidad estructural (Moutoukias, 1995), la presencia extranjera retomó su incidencia desde fines de la década de 1770, al calor del ciclo de guerras inauguradas por las revoluciones norteamericana y francesa (Villalobos, 1962; García-Baquero, 1972); la libertad de tráfico de esclavos y el comercio por vía de ensayo con colonias extranjeras, con su apelación a la portuguización (Malamud, 1985; Silva, 1996) y españolización de los navíos, entre 1791 y 1795 (Silva, 1990); el comercio con neutrales, en 1797 (Schlez, 2013; Silva, 2013); el comercio provisorio con extranjeros, en 1809 (Gelman, 2010; Schlez, 2018), y el proceso revolucionario, desde 1810 (Silva, 2010).

Y aunque la historiografía argentina advirtió desde sus orígenes que el monopolio mercantil representó una de las herramientas fundamentales de la dominación española en sus colonias, las investigaciones posteriores probaron su debilidad constituyente en el Río de la Plata y su permanente erosión a lo largo de los siglos, lo que se convirtió en uno de los fundamentos de la crisis colonial. No obstante, persiste una pregunta que aún no encuentra una respuesta definitiva en torno al periodo, etapa o proceso por el cual el monopolio español fue herido de muerte: ¿Fueron las independencias las que aniquilaron este sistema comercial? o ¿debemos referirnos a procesos tales como la libertad del tráfico negrero, el comercio con neutrales o los reglamentos provisorios de comercio con extranjeros?

Aunque nuestro trabajo no se proponga ofrecer una respuesta acabada a esta interrogante, intentaremos realizar un aporte a la cuestión retomando un antiguo observable de la historiografía: las entradas y salidas de buques comerciales de ultramar al complejo portuario rioplatense. En este sentido, puesto que el elemento central del monopolio implicaba la exclusión del tráfico de las naciones extranjeras, apelaremos a esta forma de aproximarse al problema con el objetivo de ponderar la capacidad española para excluir a sus competidores de los mercados americanos, en uno de los periodos más agudos de la guerra, cuando Napoleón bloqueaba el continente europeo y los británicos buscaban contrarrestar su poder mediante la invasión del Río de la Plata en 1806 y 1807.

\section{EL TRÁFICO PORTUARIO RIOPLATENSE DURANTE LAS INVASIONES INGLESAS: UNA TAREA PENDIENTE}

El estudio del tráfico marítimo rioplatense posee una larga tradición en la historiografía argentina, que se remonta a fines del siglo XIX con los trabajos de Lamas (1892a; 1892b), concentrados en la última década del siglo xviII y desde 1803 a la primera mitad de 1806. En ellos se observa "una considerable disminución del comercio del Río de la Plata con los puertos españoles operada en 1805 y 1806, a consecuencia de la guerra con Inglaterra, y el aumento del comercio con los puertos extranjeros europeos, Estados Unidos, Brasil y costa de África” (Lamas, 1892b, p. 135)!1

\footnotetext{
${ }^{1}$ Domingo Lamas presentó series estadísticas del movimiento portuario rioplatense para 1803-1806, asegurando haber utilizado "los estados del movimiento marítimo y las declaraciones de los corsarios que figuran en las relaciones de entradas y salidas que hemos extractado correspondientes a los años 1805 y 1806” (Lamas, 1892a, p. 103). Aunque no menciona las fuentes específicas con las que construyó sus datos, asegura que ellas "comprenden, además de las entradas y salidas de buques, sus manifiestos, nombre de sus capitanes y cargadores, así como la fecha de salida y llegada de los buques" (Lamas, 1892a, p. 98). En un estudio donde retomó y amplió sus hipótesis, Wedovoy (1955, p. 29) aseguró
} 
Posteriormente, Ravignani (1952) y Levene (1962) presentaron breves series estadísticas del movimiento portuario de Buenos Aires y Montevideo entre 1792 y 1796, las que tenían por objetivo evaluar el éxito de las reformas borbónicas, tarea para la cual se apeló a los datos presentados por el administrador de la Aduana de Buenos Aires. 2 2 Ya en la década de 1970, mientras que Garavaglia (1970) presentó series acotadas al ingreso de buques al Río de la Plata para el periodo 1779-1783, Emanuel Garcia (1973) analizó las salidas porteñas entre 1789 y 1791, dando un salto cualitativo en cuanto a la metodología para el estudio del movimiento portuario, apelando a los registros de navíos del Archivo General de la Nación de Buenos Aires y del Archivo General de Indias de Sevilla. Posteriormente, continuando la metodología de cotejar documentación sevillana y rioplatense, Silva $(1978,1984)$ inició sus análisis dedicados a aspectos particulares como la presencia estadunidense y el comercio con Hamburgo, para luego avanzar en el estudio general del tráfico con España y los principales puertos extranjeros, aportando series de entradas y salidas de buques de Montevideo para el periodo 1792-1810 (Silva, 1993). Enumeró los puertos de origen y destino de los buques, por lo que ofreció valiosa información en torno a la erosión del monopolio gaditano, aunque no presentó datos para el Río de la Plata en 1807. Pese a ello, su trabajo describe el proceso de "apertura del Río de la Plata al tráfico internacional" (Silva, 2013, p. 315) que, fundamentalmente desde la guerra anglo-española de 1796, conectó a Buenos Aires y Montevideo directamente con los principales puertos del mundo. Asimismo, a través de un pormenorizado análisis del tráfico portuario desde 1808, describió el proceso mediante el cual Buenos Aires se convirtió en base del movimiento mercantil y naviero vinculado al extranjero por sobre su par oriental (Silva, 2010, p. 204).

Con metodologías y fuentes similares, Bentancur $(1997,1998)$ reconstruyó el tráfico portuario de Montevideo a fines de la dominación española, entre 1791 y 1814 . No obstante, la imposibilidad de estudiar el comercio durante la ocupación británica a través de fuentes españolas (los registros de navíos y los libros de entradas y salidas de buques, principalmente), le impidió ofrecer datos cuantitativos para 1807. Pese a ello, los estudios de Silva y Bentancur mencionaron la existencia de una fuente alternativa que podía contribuir al estudio del tráfico en aquella coyuntura: el periódico británico, establecido en Montevideo, The Southern Star/La Estrella del Sur, que publicó sistemáticamente las entradas y salidas de barcos durante la ocupación británica ${ }^{3}$

Por su parte, Coria (1992) presentó datos del movimiento portuario para el periodo hispánico (1768-1810), agrupando en lustros su información. Aunque su periodización incluye los años 1806 y 1807, los registros de navíos del Archivo General de la Nación de Buenos Aires, excluyendo Montevideo y cualquier cruce con otro tipo de fuentes, se tornan insuficientes y no permiten tomar por válidos sus resultados. Ya en este siglo, el programa de investigación que puso en marcha Fernando Jumar $(2002,2004,2012)$ nos permitió un pormenorizado acercamiento al tráfico

que "los datos de Lamas, aunque no lo diga explícitamente, se basan en las informaciones consignadas en el Semanario de Agricultura, Industria y Comercio sobre las entradas y salidas marítimas. Comprende no sólo los barcos del tráfico de ultramar, sino también los buques entrados como presas y algunos que entraron o salieron en corso o en lastre, así como también los avisos del correo marítimo y los que se dirigían a las islas Malvinas para abastecer la guarnición, etc. No hemos verificado la exactitud de los totales dados por Lama”".

${ }^{2}$ Para el mismo periodo, también utilizó esta fuente Azcuy (2002, p. 25), agregando los datos sobre el volumen exportado, el importado y los promedios anuales.

${ }^{3}$ Los trabajos que analizaron a La Estrella del Sur lo hicieron desde la perspectiva de una historia de la imprenta, el periodismo y la cultura política (Acree, 2011; Canter, 1938; Frega y Vegh, 2007; María, 1957). El estudio de Bentancur (1998, pp. 23 y 38) utiliza el periódico sólo para ofrecer una serie de datos comerciales parciales, pero no avanza en su análisis y sistematización. 
marítimo rioplatense, desde sus orígenes hasta la sanción del Reglamento de Libre Comercio. Posteriormente, sus estudios fueron continuados por Maximiliano Camarda (2013), quien analizó la circulación de navíos del complejo portuario rioplatense en el periodo subsiguiente, entre 1778-1806. Cuestionándose en qué medida las transformaciones institucionales impactaron en los cambios sufridos por los circuitos ultramarinos, una mirada de largo plazo, que abarcó el tráfico marítimo entre 1680 y 1806, le permitió discutir las hipótesis que otorgaron a las reformas borbónicas un lugar determinante en el crecimiento del comercio rioplatense. ${ }^{4}$ No obstante, puesto que finalizó su periodización en 1806, tampoco encontramos allí un análisis del periodo de las invasiones británicas, algo que también ocurre con una importante cantidad de estudios que concentraron su mirada en la etapa posterior a la revolución de independencia, los que se interrogaron por las características de los circuitos comerciales inaugurados por la Junta de Gobierno de 1810 (Brown, 2002; Kroeber, 1967; Nicolau, 1995; Silva, 2001, 2010; Torre, 1996, 1999).

En este sentido, los estudios dedicados al comercio entre Gran Bretaña y el Río de la Plata, incluso aquellos enfocados en el estudio del transporte marítimo inglés al Río de la Plata (Albion, 1963), a pesar de notables monografías dedicadas al problema de conjunto (Pearce, 2007), no ofrecen datos estadísticos respecto del tráfico portuario para fines del siglo XVIII y principios del XIX (Schlez, 2017).

Por su parte, aunque prácticamente la totalidad de los estudios dedicados a las invasiones inglesas reconocieron al comercio como su motor principal, ninguno de ellos se dedicó al tráfico mercantil que el ataque militar desencadenó. Entre las escasas referencias sobre el tema, se destaca un dato sistemáticamente repetido: una invasión acompañada por una enorme flota mercante de entre 100 (Bentancur, 1998; Hughes, 2013, p. 85; Roberts, 2006, p. 226; Street, 1967); y 150 navíos (Crouzet, 1958). El problema de este dato es que la afirmación original, realizada por Roberts hace ochenta años, no señaló la fuente que sustentó su aseveración, mientras que quienes la retomaron se limitaron a realizar la cita de autoridad sin verificar el origen de la afirmación. $5^{5} \mathrm{La}$ excepción es Crouzet (1958), quien apeló a los datos ofrecidos por los customs británicos, pero no avanzó en una descripción de los puertos de origen, ni tampoco en el análisis del destino que tuvieron los buques invasores luego de abandonar el Río de la Plata. Y aunque mencionó la apertura de los puertos a buques neutrales durante la invasión, no describió ni ponderó su participación.

\footnotetext{
${ }^{4}$ Mientras que para el periodo 1680-1778 apeló a los estudios de Jumar, basados fundamentalmente en registros de navíos, la etapa 1779-1806 fue analizada por Camarda mediante el epistolario periódico entre el gobernador de Montevideo y el virrey, que menciona los navíos de entrada al Río de la Plata, generalmente a Montevideo.

${ }^{5}$ Por ejemplo, Hughes (2013) y Street (1967) simplemente citan a Roberts (2006), al tiempo que Bentancur (1998) cita a Street. Esto no quiere decir que la obra de Roberts no se encuentre documentada. El problema es que no aclara debidamente el origen de las informaciones vertidas en su relato, limitándose a citar las fuentes trabajadas al final del trabajo, entre las que se destacan los expedientes del Archivo Nacional de Londres (War Office, Admiralty, Foreign Office, Treasury, Colonial Office, Audits, Home Office, el Archivo de las familias Pitt, Wyndham y Grenville) y la Biblioteca Británica (sección manuscritos, archivos de Stowe, Egerton, Vansittart, Parish, Wellesley, Windham, Liverpool, Huskisson y Canning). Por su parte, en el Río de la Plata apeló a los principales repositorios (AGN, Museo Mitre, Biblioteca Nacional, etc.), aunque tampoco señaló los fondos utilizados. Actualmente, la colección privada de fuentes adquiridas por Roberts, junto a las fuentes que trabajó, pueden consultarse en el AGN de Argentina.
} 


\section{OBjetivos, METODOLOGíA y FUENTES}

El balance historiográfico nos muestra que, en el Río de la Plata: a) el monopolio mercantil español se caracterizó por su incapacidad para restringir la presencia extranjera desde sus periodos fundacionales -en los siglos XVI y XVII-; b) en el siglo XVIII la corona española intentó resolver esta falencia por medio de reformas políticas y administrativas, con resultados contradictorios e insuficientes frente al ciclo de guerras iniciado en 1779, que devolvió el protagonismo al tráfico con puertos extranjeros.

Sin embargo, en este desarrollo no se han realizado análisis sistemáticos del tráfico comercial portuario durante el periodo de la invasión británica a Buenos Aires y Montevideo -entre junio de 1806 y septiembre de 1807- por lo que no podemos ponderar su lugar en este proceso. Probablemente, este vacío historiográfico encuentra su origen en la imposibilidad de observar dicho tráfico mediante la documentación española (de ambos lados del Atlántico), usualmente utilizada para el estudio del comercio colonial debido a que no registró el movimiento portuario durante la ocupación extranjera.

Nuestro artículo busca superar estos problemas a partir de una aproximación al tráfico portuario rioplatense durante la invasión inglesa al Río de la Plata, recurriendo a documentación serial oficial, publicaciones periódicas y fuentes cualitativas, como correspondencia y memorias de los actores, tanto británica como española. En The National Archives (TNA), en Kew, Londres, Gran Bretaña, recurriremos a los Records of the Boards of Customs, Excise, and Customs and Excise, and HM Revenue and Customs (CUST) de Gran Bretaña e Irlanda. Particularmente, los States of Navigation, Commerce and Revenue (Cust 17), los Ledgers of Imports Under Countries británicos (CUST 4) y los libros de comercio exterior de Escocia (CUST 14) e Irlanda (CUST 15), todos para los años 1806 y 1807. Asimismo, intentaremos completar los datos ausentes y lagunas a partir de informes privados del Privi Council (Exports to River Plate. Restitution of Seized Property, 1807 (PC 1/3763) y de la correspondencia entre los jefes militares en el Río de la Plata y el gobierno británico (tomadas del ya clásico repositorio War Office, 1/162, TNA), y de comerciantes monopolistas españoles, tomadas de la colección Papers of the Government of Buenos Ayres. English Invasions, resguardada en la British Library, y del Archivo General de la Nación de Montevideo de Uruguay (AGN-U).

Para el Río de la Plata, utilizaremos el libro maestre de entrada de buques, del periodo 18051818 (Fondo Archivo General Administrativo, Capitanía del Puerto), los Registros de Navíos del año 1806 (Fondo Ex Archivo y Museo Histórico Nacional, Aduana de Montevideo, ambos en AGN-U), y los archivos del cabildo de Buenos Aires, resguardados en el Archivo General de la Nación, Argentina (AGN-A). También recurriremos al resumen general de los navíos que partieron desde Montevideo a puertos extranjeros -entre 1802 y 1806-, confeccionado por el responsable de la Aduana oriental y resguardado en el Archivo General de Indias, Sevilla (AGI).

Finalmente, apelaremos a fuentes éditas: evaluaremos el periodo de la ocupación británica de Montevideo a través del ya mencionado periódico The Southern Star/La Estrella del Sur, que ofreció datos del movimiento portuario hasta el momento no trabajados por la historiografía, y apelaremos también a periódicos británicos (The Times, The Caledonian Mercury), memorias de militares y comerciantes, así como al juicio realizado al comandante británico, Home Popham, en Londres, luego de su derrota. 


\section{El ATAQue a Buenos Aires: PRimera DeRrota Del COMERcio DiRecto POR INVASIÓN}

A fines del siglo XVIII, las colonias españolas de América del Sur constituían un preciado objetivo para Gran Bretaña y, pese a existir un muy limitado comercio directo, fruto de permisos coyunturales, los mercados sudamericanos no estaban al alcance de los comerciantes británicos sino a través del contrabando, el fraude y la navegación en buques de otras naciones ${ }^{6}$ En este sentido, aunque la invasión al Río de la Plata, comandada por Popham, Beresford y Baird, fue considerada una aventura militar individual, se trató de una expedición largamente meditada, e incluso alentada por sectores del capital mercantil británico (A full and correct report, 1807, p. 212).

El carácter sorpresivo que debía tener la invasión, que incluso fue comunicada a la propia corona británica cuando ya se encontraba lanzada.7 impidió a los comerciantes británicos sumarse a ella desde su inicio, por lo que sólo tres buques mercantes se unieron a esta expedición militar en la isla de Santa Elena, adonde Popham había recalado, proviniendo desde el Cabo de Buena Esperanza, para sumar fuerzas y tropas para el ataque 8 Se convertirían en los primeros comerciantes en verse beneficiados de la ocupación de Buenos Aires, aunque representaban una fuerza absolutamente insuficiente para enfrentar la tarea de reemplazar a sus competidores españoles y abastecer los mercados sudamericanos.

La primera tarea de la que se encargó Home Popham, al mismo tiempo que Beresford firmaba la capitulación de las fuerzas españolas $\unlhd^{9}$ fue informar a Londres de la toma de Buenos Aires y convocar a sus comerciantes a acudir masivamente al Río de la Plata. ${ }^{10}$ Pocos días después, Beresford decretó la apertura del puerto de Buenos Aires al comercio libre con todas las naciones del mundo, estableciendo el marco legal para el inicio de la invasión mercantil ${ }^{11}$ No obstante, la rápida reconquista de las fuerzas españolas -47 días después- abortó el proceso antes de que este se hubiera puesto en marcha, pues las novedades de la toma de la capital del virreinato ni siquiera habían llegado a Londres cuando la bandera británica fue arriada del fuerte de Buenos Aires.

\footnotetext{
${ }^{6}$ Son conocidas las manipulaciones que realizaban los comerciantes de las leyes y disposiciones para obtener permisos de comercio directo, fluctuando entre la ilegalidad y el fraude. Por ejemplo, la fragata inglesa Caña Dulce o Caña de Azúcar, que había partido de Londres en julio de 1795, con destino a la costa de África, arribó a Montevideo en diciembre con carga de 228 negros y, gracias a la combinación de las reales órdenes sobre tráfico de negros con la que permitía el tráfico por vía de ensayo con colonias extranjeras, sus destinatarios (los hermanos -el Conde y SantiagoLiniers) gestionaron su carga en el Río de la Plata (solicitando se permita incluir cueros y sebo, lo que fue denegado) para que el buque regresara, directamente a Inglaterra. Buenos Aires, 122, Archivo General de Indias (en adelante AGI).

${ }^{7}$ Carta de David Baird, Ciudad del Cabo (14 de abril de 1806); Home Popham a Lord Viscount Castlereagh, Santa Elena (30 de abril de 1806). War Office, 1/161, The National Archives (en adelante TNA).

8 "La expedición también fue reforzada por tres navíos mercantes anclados en la bahía, entre ellos el Justina, un barco inglés de veintiséis cañones pertenecientes a los señores Princeps y Saunders, de Londres. Persuadidos que por su carga de 'artículos diversos para la especulación' obtendrían un alto precio en un Buenos Aires 'liberado', William Dunn, el supercargo del barco, y Robert Morris, su capitán, abandonaron su aventura original: un viaje a Botany Bay a través de Ciudad del Cabo, y se unieron al escuadrón de Popham” (Hughes, 2013, p. 25, citando PG 1/3823, original en inglés, traducción propia).

${ }^{9}$ Terms of Capitulation (2 de julio de 1806), War Office, 1/161, TNA.

${ }^{10}$ Home Popham a Lord Viscount Castlereagh (14 de julio de 1806), Hms Diadem, Rio de la Plata, War Office, $1 / 161$, TNA.

${ }^{11} 1^{\circ}$ and $2^{\circ}$ Proclamation of the Lieutenant Governor of Buenos Ayres and all its dependencies W. C. Beresford (11 de julio de 1806), Fuerte de Buenos Aires; Duties on Exports and Imports (11 de julio de 1806), War Office, 1/161, TNA.
} 
Pero el rechazo de la invasión no provocó la retirada de las fuerzas británicas y una enorme flota permaneció bloqueando la puerta del Río de la Plata, esperando refuerzos para recomenzar el ataque. Desde mediados de 1806, los capitanes de los buques neutrales que arribaron a Montevideo comenzaron a informar de la presencia militar inglesa, que los obligaba a presentar la documentación pertinente para continuar su viaje al puerto. Por ejemplo, el 22 de junio de 1806, una fragata hamburguesa divisó una flota de guerra inglesa compuesta por 31 buques ${ }^{12}$ Poco después, el 26 de agosto, la fragata estadunidense Thampor, proveniente de Nueva York, comunicó que los británicos ya se encontraban bloqueando el puerto rioplatense, informe que repitió el 14 de septiembre la fragata María, de Baltimore, Estados Unidos. Todos estos testimonios fueron realizados en Montevideo porque, efectivamente, el bloqueo británico no les impidió su ingreso.

Sin embargo, no ocurrió lo mismo luego de la derrota de la primera oleada invasora, cuando la flota inglesa comenzó a retener en Maldonado a los buques neutrales que arribaban al Río de la Plata desde octubre de 180613 Una fuente cualitativa nos ofrece un panorama general de la enorme flota invasora en aquella coyuntura: "La flota británica era la más impresionante que se había visto en el Río desde la expedición del virrey Cevallos. Cuatro barcos de línea, dos fragatas, dos gun-brigs ${ }^{14}$ un barco de suministros, doce transportes y más de cuarenta navíos mercantes, tanto neutrales como enemigos, detenidos por intentar romper el bloqueo, estaban anclados en los caminos" 15

Mientras tanto, las novedades de la conquista, junto a la invitación de Popham a los comerciantes británicos, llegaron a Londres en septiembre de 1806 ${ }^{16}$ Desde entonces, se desató una carrera por enviar buques mercantes al territorio ocupado con el fin de que las manufacturas se expandieran desde allí a los principales mercados de América del Sur. Según los libros de aduana británicos, viajaron al Río de la Plata 51 navíos comerciales, antes que el año finalizara $\sqrt{17}$ Puesto que este cálculo se refiere a Inglaterra y Escocia (excluyendo Irlanda), y no menciona los puertos específicos desde donde partieron los buques, apelamos a un documento del consejo privado de su majestad británica (privi council), que poseía entre sus papeles una "Copia de las Exportaciones salidas hacia el Río Plata (sic) el 4 de octubre de 1806, tomada de la aduana de Londres" (véase gráfica 1).

Dicho documento nos muestra que fueron 71 los navíos mercantes los que partieron desde diversos puertos británicos, entre los que, más allá de la preeminencia de Londres (30 navíos), se destaca el aporte de Liverpool (once buques), Guernsey-Jersey (ocho barcos) y Glasgow (cinco navíos). Asimismo, vemos que también fueron protagonistas Bristol, Hull, Grismby, y hasta Gales

\footnotetext{
${ }^{12}$ Libro maestre de entrada de buques, 1805-1818, 4C, núm. 95. Capitanía del Puerto, Fondo Archivo General Administrativo, Archivo General de la Nación de Montevideo de Uruguay (en adelante AGN-U).

${ }^{13}$ Ese fue el caso de las fragatas Mariana y Vennerner (dinamarquesas); La Jenny y Die Juliana (hamburguesas) y Las Dos Hermanas (nave española, simulada portuguesa). Libro de entrada de buques, 1805-1818, 4C, núm. 95. Capitanía del Puerto, Fondo Archivo General Administrativo, AGN-U.

${ }^{14}$ Se trata de pequeños buques de guerra, en general menores a 200 toneladas. Véase Winfield (2008).

15 “Anónimo" (13 de octubre de 1806), en The Caledonian Mercury, 2 de febrero de 1807. Recuperado de The British Newspaper Archive, en http://www.britishnewspaperarchive.co.uk (original en inglés, traducción propia).

${ }^{16}$ Popham to "The Mayor and Corporation of Birmingham" (1 de julio de 1806), Buenos Ayres. Reproducido en The Times (20 de septiembre de 1806), recuperado de http://www.thetimes.co.uk/archive/

${ }^{17}$ States of Navigation, Commerce and Revenue, 1806, CuST 17/28, TNA.
} 
GRÁFICA 1. BUQUES SALIDOS HACIA EL RÍO DE LA PLATA
DESDE LAS ISLAS BRITÁNICAS (OCTUBRE DE 1806)

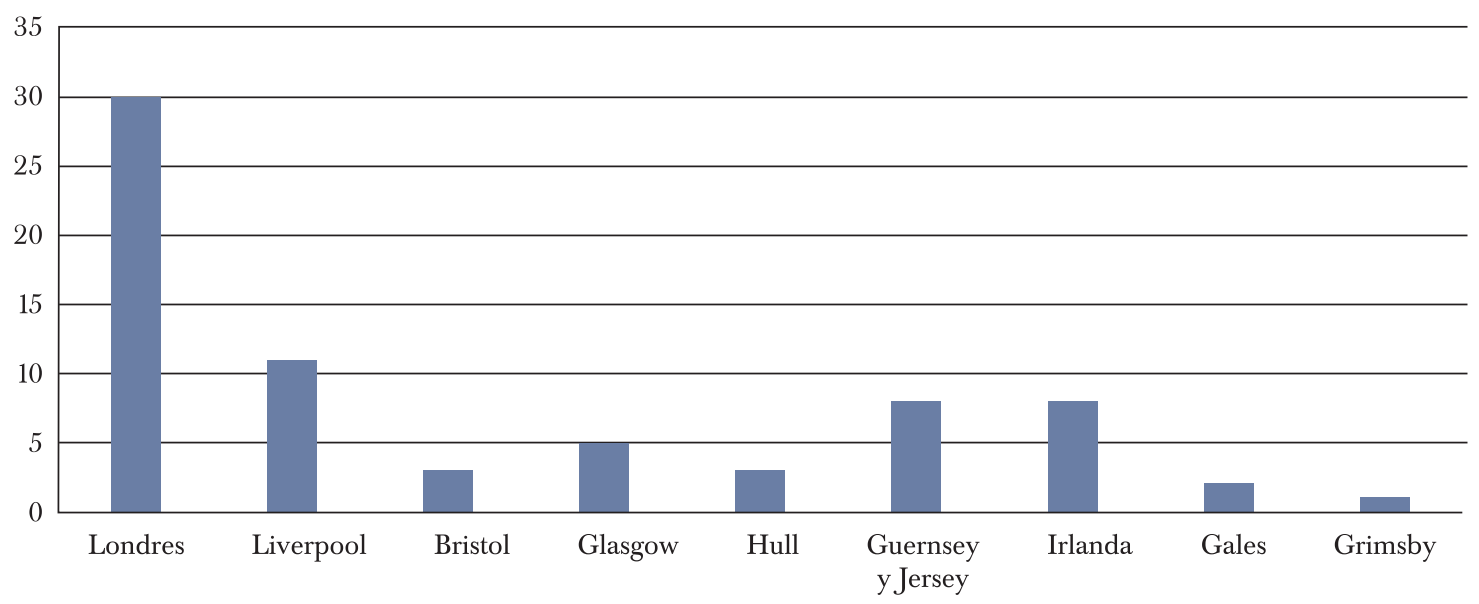

Puerto de origen

Fuente: Exports to River Plate, Restitution of Seized Property, 1807, PC 1/3763, TNA.

e Irlanda. Y aunque esta fuente no menciona los puertos irlandeses desde los que partieron los navíos hacia Buenos Aires, los libros de exportación de ese país nos muestran que lo hicieron desde Belfast, Dublín y London Derry. 18

Estos 71 buques mercantes -que partieron en octubre de 1806- comenzaron a arribar al Río de la Plata entre fines de año y principios de 1807, momento en que los británicos reiniciaron la invasión. Asimismo, en 1807, fueron remitidos otros 17 buques mercantes más desde Inglaterra y Escocia (no poseemos datos de Irlanda, desde donde también se registran exportaciones, pero sus libros no especifican datos de navegación). ${ }^{19}$ Por lo tanto, teniendo en cuenta los cuarenta buques comerciales, británicos y neutrales que aguardaban en el Río de la Plata, más los que partieron desde Gran Bretaña, la invasión sumaba, entre diciembre de 1806 y febrero de 1807, un total estimado de 111 navíos mercantes.

Según el testimonio de uno de los capitanes de los navíos mercantes que participaron en la invasión, ellos fueron "enviados a Buenos Aires como consecuencia de las atractivas perspectivas planteadas por Sir Home Popham” y, en su gran mayoría, llegaron a principios de 1807, puesto que, tal como informó el propio Popham de regreso a Londres, cuando abandonó el Río de la Plata -en la navidad de 1806- sólo estaban en el Río de la Plata, provenientes de Inglaterra, el Duke of Kent (al mando del capitán Robinson), el Anna (capitán Eastwick al frente, autor de las memorias), y el Spring-Grove (a cargo del capitán Greenwood), mismos que permanecieron en Maldonado bajo el mando del almirante Stirling (Eastwick, 1891, p. 226). A medida que los navíos mercantes iban llegando, sin posibilidad de acceder a Buenos Aires debido a su inmediata recuperación por las armas locales (Bentancur, 1998, pp. 15-16), se sumaron a la flota militar británica, participando activamente del bloqueo del Río de la Plata (Hughes, 2013, p. 110).

\footnotetext{
${ }^{18}$ Exports and Imports of Ireland, Exports to Buenos Ayres, 1806, Cust 15/110, TNA.

${ }^{19}$ States of Navigation, Commerce and Revenue, 1807, CUST 17/29; Las exportaciones irlandesas correspondientes a 1807 , CUST $15 / 110$, ambos en TNA.
} 
En febrero de 1807, las fuerzas británicas iniciaron la invasión y ocupación de Montevideo, hecho que fue registrado por los libros de la aduana del puerto en los siguientes términos: "en 11 de diciembre de 1806 fue el último buque que entró en este puerto por el restante del mes y todo el mes de enero estuvimos bloqueados e invadidos por los ingleses, los que se apoderaron por asalto de este puerto y plaza la madrugada del día 3 de febrero de 1807" 20 Desde entonces, los buques mercantes tuvieron acceso a los mercados rioplatenses, por lo que concluimos, tal como se desprende de los datos, hechos y testimonios presentados, que la invasión comercial británica no recayó, en un principio, sobre Buenos Aires, sino que se desarrolló al calor de la ocupación de Montevideo. Es por ello que, teniendo en cuenta el flujo de buques mercantes, tanto británicos como neutrales, que hacia allí se dirigieron, una mirada más certera nos exige trasladarnos a la Banda Oriental.

\section{MONTEVIDEO BAJO OCUPACIÓN BRITÁNICA:}

DEL TRÁFICO CON NEUTRALES AL COMERCIO DIRECTO POR INVASIÓN

Durante el quinquenio previo a la invasión británica, el Río de la Plata se vinculó con una importante cantidad de puertos no españoles, fundamentalmente, gracias al permiso de exportar mercancías rioplatenses al extranjero a cambio de introducir esclavos (lo que en las fuentes españolas se denomina producto de negros y cuya vigencia data de 1791) y al denominado comercio de ensayo (establecido en 1795). En este sentido, según la documentación de la aduana de Montevideo, confeccionada por el responsable del puerto y refrendada por el secretario del Consulado de Buenos Aires, Manuel Belgrano, entre 1802 y 1806 salieron 223 navíos con destinos no españoles (véase gráfica 2).

Como podemos ver, entre los principales destinos se destacan los puertos de la actual Alemania (Hamburgo, Tonning), que recibió 23 barcos que representaron $10 \%$ del total; Francia (Burdeos, Marsella, Saint Maló, Dunquerque, la isla africana de Mauricio -bajo control francés-, y Cayena, capital de la Guayana Francesa) destacó con 19 buques (9\%); Reino Unido con once navíos (5\%); Estados Unidos (Filadelfia, Charleston, Newport) acogió nueve buques (4\%) y Portugal (Lisboa, Oporto) cuatro ( $2 \%)$. Lo que da cuenta de una paridad entre las principales potencias ascendentes, mismas que buscaban disputarle a España su monopolio comercial, particularmente la fuerte presencia de alemanes (Aristizábal, 2018; Silva, 1984) y franceses. No obstante, los mayores porcentajes representan una incógnita pues 44 \% de los navíos (98) partió hacia las denominadas colonias extranjeras sin mayor referencia. Y aunque podemos suponer, como señala la historiografía, que en la mayoría de los casos la categoría refiere a puertos del Brasil, también es cierto que, muy probablemente, desde allí continuaron su viaje a diversos puertos del mundo, por lo que su destino final no puede ser discernido a partir de esta documentación. Tampoco conocemos el destino de $17 \%$ de los buques (38) que la fuente consigna como sin denominación; es decir, que no declararon -o no quedó registro- adónde se dirigían. Finalmente, debemos advertir que este tipo de fuente serial no nos permite observar los fraudes de doble registro; es decir, aquellos navíos que simularon tanto su destino como su nacionalidad, los cuales salen a la luz a través de la correspondencia mercantil de los mercaderes. Por ejemplo, el 5 de octubre de 1803, Dardo Estrada informaba, desde Mon-

\footnotetext{
${ }^{20}$ Libro maestre de entrada de buques, 1805-1818, 4C, núm. 95. Capitanía del Puerto, Fondo Archivo General Administrativo, AGN-U.
} 


\section{GRÁFICA 2. PAÍSES DE DESTINO DE BUQUES SALIDOS DE MONTEVIDEO DIRIGIDOS A PUERTOS EXTRANJEROS (1802-1806)}

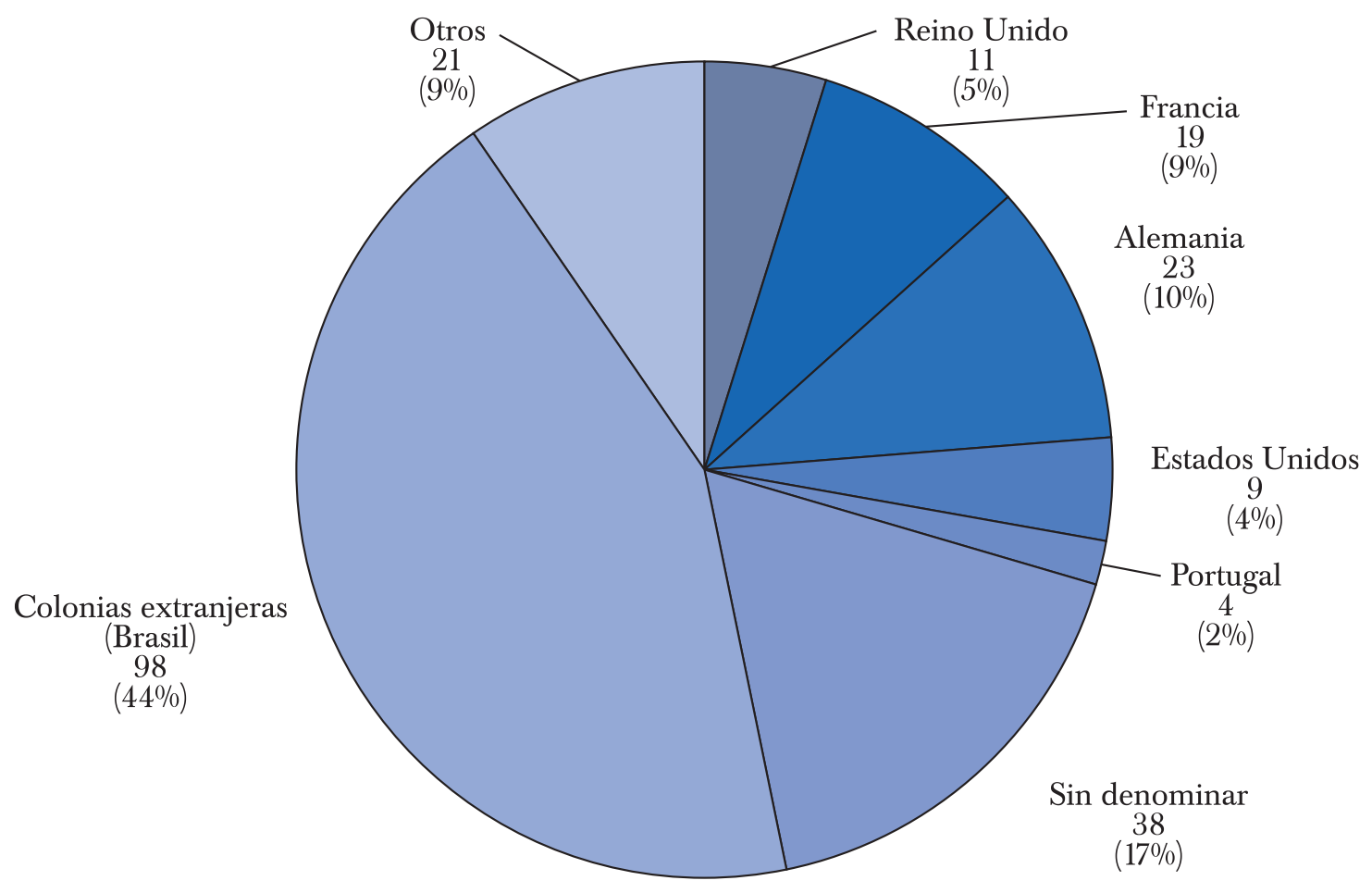

Nota: la gráfica señala el número de navíos salidos y el porcentaje sobre el total.

Fuente: Resumen General que manifiesta los frutos, efectos y caudales de los buques despachados por la Real Aduana de este Puerto en los años de 1802 a 1806 inclusive, con destino a Puertos Colonias extranjeras y África, Gregorio Calzadilla, Montevideo, 31 de diciembre de 1806. Buenos Aires, 94, AGI.

tevideo, a sus socios en Londres, Cádiz y La Coruña que Martín de Álzaga remitía mercancías en la fragata angloamericana José of Kennebunk, su capitán y maestre, Juan Francisco Agrícola, advirtiendo que ella partiría:

con Patente, registro y bandera española [...] despachado por esta aduana con dirección a la costa de África a la compra de negros, pero su destino será al de Londres con patente, tripulación y bandera americana al cargo de su verdadero capitán y dueño don Juan Grant que se ha constituido a virtud de los documentos simulados que se están disponiendo y debe llevar a la mano a defender este cargamento como suyo propio en cualquiera encuentro o reconocimiento que le sobrevenga durante su viaje con ingleses y franceses hasta que se realice la entrega a sus legítimos interesados (Silva, 1990, p. 67).

Sobre el comercio con Gran Bretaña, la fuente nos muestra que, al igual que el resto, fue llevado adelante como parte de los permisos para los tratantes de esclavos que, luego de introducirlos en el Río de la Plata, se encontraban habilitados para exportar frutos rioplatenses a puertos extranjeros. Fue así como, en 1802, un navío se dirigió a Londres; en 1803 viajaron tres a Londres, 
uno a Falmouth y uno a Gibraltar; en 1804, cuatro a Londres; en 1805, uno a Norfolk ${ }^{21}$ y no hay registros de viajes al Reino Unido para 1806. Estos datos nos permiten sacar a la luz un tráfico que se encuentra oculto en las fuentes británicas. En este sentido, revisados los libros oficiales de exportación e importación entre 1796 y 1806, sólo se registra un vínculo comercial con Buenos Aires en 18002 En el interregno de paz entre España y Gran Bretaña, entre 1802 y 1804, los libros británicos señalan que, en 1803 se importaron mercancías desde las colonias españolas americanas por un valor de 157749 libras (valor oficial), al tiempo que se exportaron mercaderías por sólo 375 libras, pero no se especifica el contenido de la categoría. Lo mismo ocurre en 1805, cuando se registra comercio con las colonias españolas americanas (impulsado por ocho navíos -cuatro británicos y cuatro extranjeros-), mientras que las fuentes escocesas advierten sobre importaciones provenientes de América del Sur. No obstante, ninguna especifica los puertos que comprenden ambas categorías. Finalmente, en 1802 y en 1804 el vínculo con el Río de la Plata se encuentra escondido tras la denominación Indias Occidentales extranjeras, por lo que no podemos descartar vínculos comerciales directos en 1796, 1797 y 1801, años en que también se registra un volumen mercantil con las Indias Occidentales extranjeras, pero su confirmación exige el análisis de fuentes rioplatenses 23

Más allá de estas especulaciones, los datos del periodo 1802-1806 muestran que el violento ataque británico al convoy español que se dirigía a Cádiz desde Montevideo, a fines de 1804, y que condujo a una nueva guerra anglo-española, tuvo como resultado una disminución de la cantidad de navíos mercantes dirigidos a Inglaterra desde el Río de la Plata en los años inmediatamente posteriores. Asimismo, este nutrido tráfico de buques neutrales que caracterizaba al puerto de Montevideo, expresaba el notable repliegue del comercio colonial español luego de esta nueva declaración de guerra: los dos años siguientes, sólo doce navíos (cinco en 1805 y siete en 1806), lograron realizar un comercio directo entre la metrópoli y el Río de la Plata (Silva, 1993). ${ }^{24}$ Golpe que no sólo afectó a la dirección del tráfico marítimo, sino también al transporte que soportaba el tráfico, es decir, al pabellón o bandera de los navíos, tal como muestran los registros de los 52 navíos que se han conservadd 25 (véase gráfica 3 ).

A partir de estos registros, se observan las dificultades que atravesaba la navegación española, ya que sólo tres de los buques salidos poseían pabellón español. También es significativa la ausencia de buques británicos en la navegación rioplatense, lo que no implica que sus comerciantes y mercancías estuviesen ausentes de los mercados rioplatenses, puesto que ellas eran traficadas por los propios comerciantes españoles, o bien en expediciones resultantes del tráfico de esclavos (como

${ }^{21}$ Puesto que la fuente sólo menciona el nombre del puerto, no podemos confirmar que este navío se haya dirigido a Norfolk, Inglaterra (tal como sospechamos), o a Norfolk, Virgina, Estados Unidos.

${ }^{22}$ Cuando fueron importadas a Inglaterra mercancías por 410 libras esterlinas, según valor oficial. Buenos Aires formaba parte, según la clasificación británica, de las Indias Occidentales extranjeras (Foreign West Indies), junto a Cayena, Cuba, San Bartolomé, la isla de Santa Cruz, Santo Domingo, la isla de San Martín, Santo Tomás y Cuba. Londres, cust $17 / 22$, TNA.

${ }^{23}$ A diferencia de los años 1798 y 1799, cuando se especifica el contenido de las Indias Occidentales extranjeras para esos años, que no incluyó al Río de la Plata, y que fue conformada por Guadalupe, Surinam, San Bartolomé, Yucatán (Honduras), la isla de Santa Cruz, Cuba y Santo Tomas y Curazao, Londres, cust 17/18 al 27 y 14/18, TNA.

${ }^{24}$ No obstante, no podemos inferir de esta información que la totalidad de los buques que declararon su partida a puertos extranjeros no haya concluido su viaje en puertos españoles, en tanto, como probó la historiografía, buena parte del tráfico entre la metrópoli y sus colonias se sostuvo por medio de navíos y puertos neutrales, fundamentalmente, portugueses (Schlez, 2016a. p. 171).

${ }^{25} \mathrm{El}$ resumen general al que hicimos referencia previamente señala que la totalidad de buques salidos en 1806 fueron 77 , por lo que no se habrían conservado, en el repositorio uruguayo, 25 registros de navíos. 
GRÁFICA 3. BANDERA DE BUQUES SALIDOS DE MONTEVIDEO (1806)

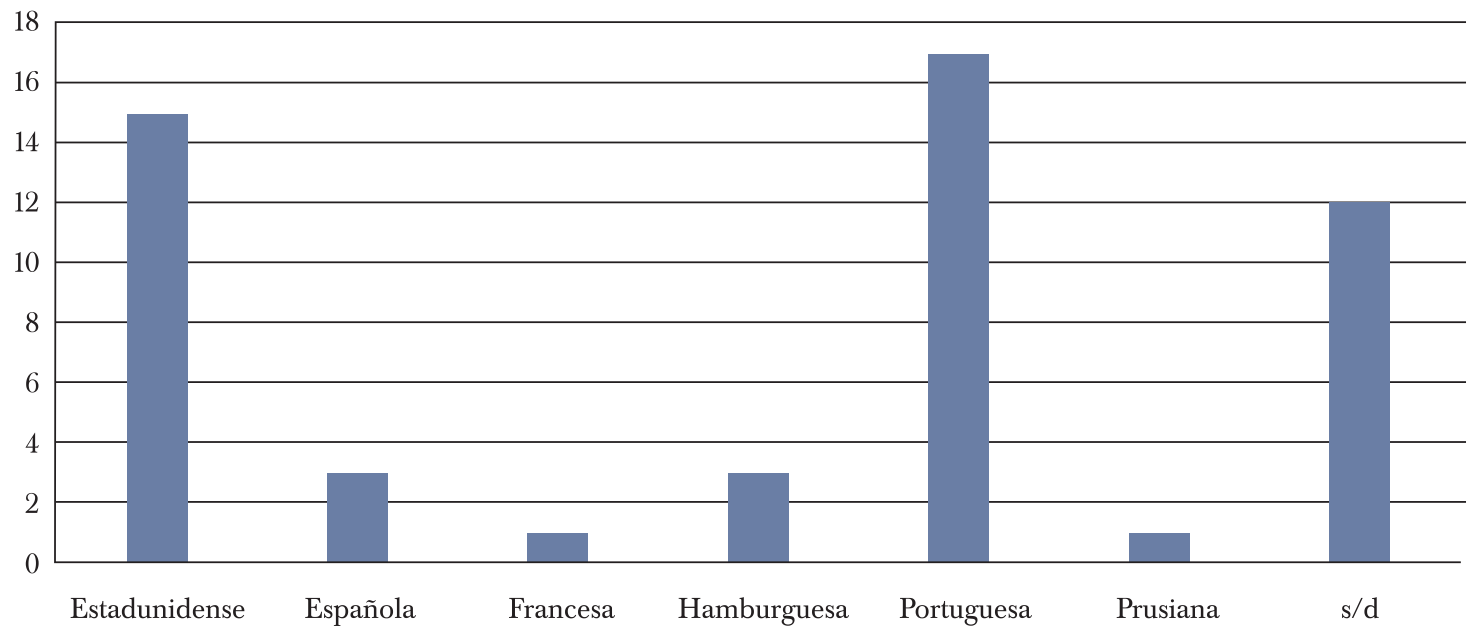

Fuente: Registros de Navíos, 1806, Aduana de Montevideo, Fondo Ex Archivo y Museo Histórico Nacional, AGN-U.

vimos más arriba); bien por medio de un comercio de reexportación desde Cádiz (Schlez, 2016b), o a través del comercio de neutrales, a través de mercaderes y buques estadunidenses (Silva, 1978; Pearce, 2007).

Por su parte, si avanzamos a 1807, el análisis de los pabellones de los buques ingresados durante el periodo de la invasión inglesa, a partir de la documentación española (véanse gráficas 4 y 5), nos muestra la permanencia de un amplio número de navíos extranjeros, no sólo británicos, que continuaron comerciando con el Río de la Plata. Ello obedeció a que, al igual que Beresford en Buenos Aires, Auchmuty autorizó el comercio con neutrales en Montevideo luego de la ocupación de la plaza 26

No obstante, respecto del pabellón de buques que registra la gráfica 3 , debe tenerse en cuenta que una porción indefinida de los navíos que aparecen como portugueses son, en realidad, españoles que apelaban a la denominada simulación, o portuguización, para atravesar los mares como neutrales (Silva, 1996) ${ }^{27}$ Más allá de esto, es evidente que tanto los puertos como los buques portugueses (y también los estadounidenses) no abandonaron su importancia para el comercio rioplatense durante el periodo de las invasiones. Incluso, también puede advertirse una importan-

\footnotetext{
${ }^{26}$ Samuel Auchmuty a William Wyndham (7 de febrero de 1807), Montevideo, War Office, 1/162, tNA. Posteriormente, se solicitó desde Downing Street que dicha medida no se extendiera más allá de los ocho meses dispuestos, para no perjudicar a los comerciantes británicos: "Es conveniente abrir el Puerto de Montevideo a neutrales para vinos y licores durante ocho meses. De la necesidad de esta medida, de la que los comerciantes británicos se quejan mucho, es difícil a esta distancia formar un juicio. Sin embargo, debo recomendar que esta indulgencia no se extienda, y si usted está en posesión de Buenos Aires, probablemente no habrá ninguna necesidad de extenderla a ese Puerto”, Lord Castlereagh al T. General Whitelocke, Downing Street (8 de junio de 1807), Londres, War Office, 1/162, TNA (original en inglés, traducción propia).

${ }^{27}$ A modo de ejemplos, el libro de entradas de buques de Montevideo señala que el bergantín español La Encarnación, proveniente de Río de Janeiro y propiedad del comerciante español Mateo Magariños, navegaba simulando bandera portuguesa, al igual que la fragata Las Dos Hermanas, proveniente de Oporto, la que también era de bandera española y simulada portuguesa, que luego de la expulsión de los británicos se dirigió a La Habana. Libro maestre de entrada de buques, 1805-1818, 4C, núm. 95. Capitanía del Puerto, Fondo Archivo General Administrativo, AGN-U.
} 


\section{GRÁFICA 4. BANDERA DE BUQUES ENTRADOS A MONTEVIDEO (JUNIO, 1806-NOVIEMBRE, 1807)}

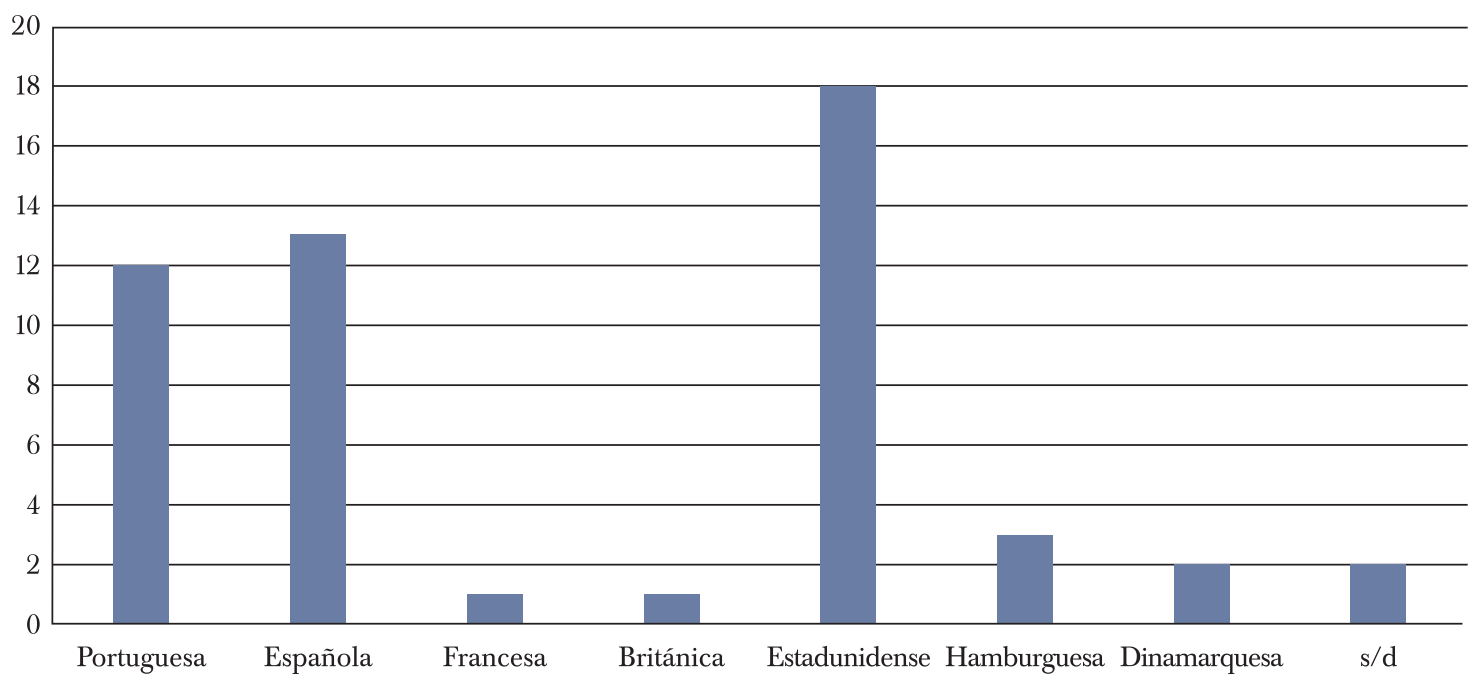

Fuente: Libro maestre de entrada de buques, 1805-1818, 4C, núm. 95. Capitanía del Puerto, Fondo Archivo General Administrativo, AGN-U.

te presencia de buques españoles que resistían el avance de sus enemigos. Al respecto, la gráfica 4 muestra los primeros signos de un incipiente comercio directo entre el Río de la Plata y Gran Bretaña que, dada las características de la fuente (el libro de entradas de buques de la aduana de Montevideo) no puede observarse en toda su magnitud, debido a que las autoridades portuarias españolas fueron reemplazadas por la administración británica y, posteriormente, sólo lograron recuperar la información de tan sólo ocho buques entrados durante la ocupación británica entre febrero y septiembre de 1807.

Ahora bien, si las fuentes británicas nos informan que más de un centenar de buques se dirigieron al Río de la Plata y la documentación española se torna insuficiente para comprobarlo - por no existir registros de semejante movimiento- ¿cómo aproximarnos al tráfico marítimo durante la invasión británica al Río de la Plata? La respuesta la encontramos, siguiendo las pistas de la historiografía, en el periódico británico The Southern Star/La Estrella del Sur (1807). Publicado en Montevideo por los invasores como propaganda de la dominación británica y la libertad de comercio, ofreció datos sistemáticos del tráfico portuario en un periodo en que las fuentes españolas no ofrecieron registro alguno, es decir, desde la apertura de la aduana controlada por los británicos, el 4 de febrero de 1807, en un servicio ofrecido "para la información de nuestros amigos comerciantes", tal como resumió su editor.28

Aunque la conclusión de los debates metodológicos en torno a la utilización de series construidas a partir de publicaciones periódicas advierten que estas no dejan de constituir un eco más o menos lejano, del movimiento naviero real ${ }^{29}$ lo cierto es que la necesidad de apelar a este tipo

${ }^{28}$ The Southern Star/La Estrella del Sur (23 de mayo de 1807), núm. 1, p. 4 (original en inglés, traducción propia).

${ }^{29} \mathrm{El}$ concepto de eco fue propuesto por Antonio García-Baquero para definir el grado de fiabilidad de las Gazette d’Amsterdam, en su debate con Michel Morineau, respecto de las fuentes para medir el volumen del tráfico entre España y sus Indias. García-Baquero (2003, p. 32) encontró unas 480 arribadas de registros de navíos con caudales americanos 


\section{GRÁFICA 5. PUERTO DE ORIGEN DE BUQUES INGRESADOS A MONTEVIDEO (JUNIO, 1806-NOVIEMBRE, 1807)}

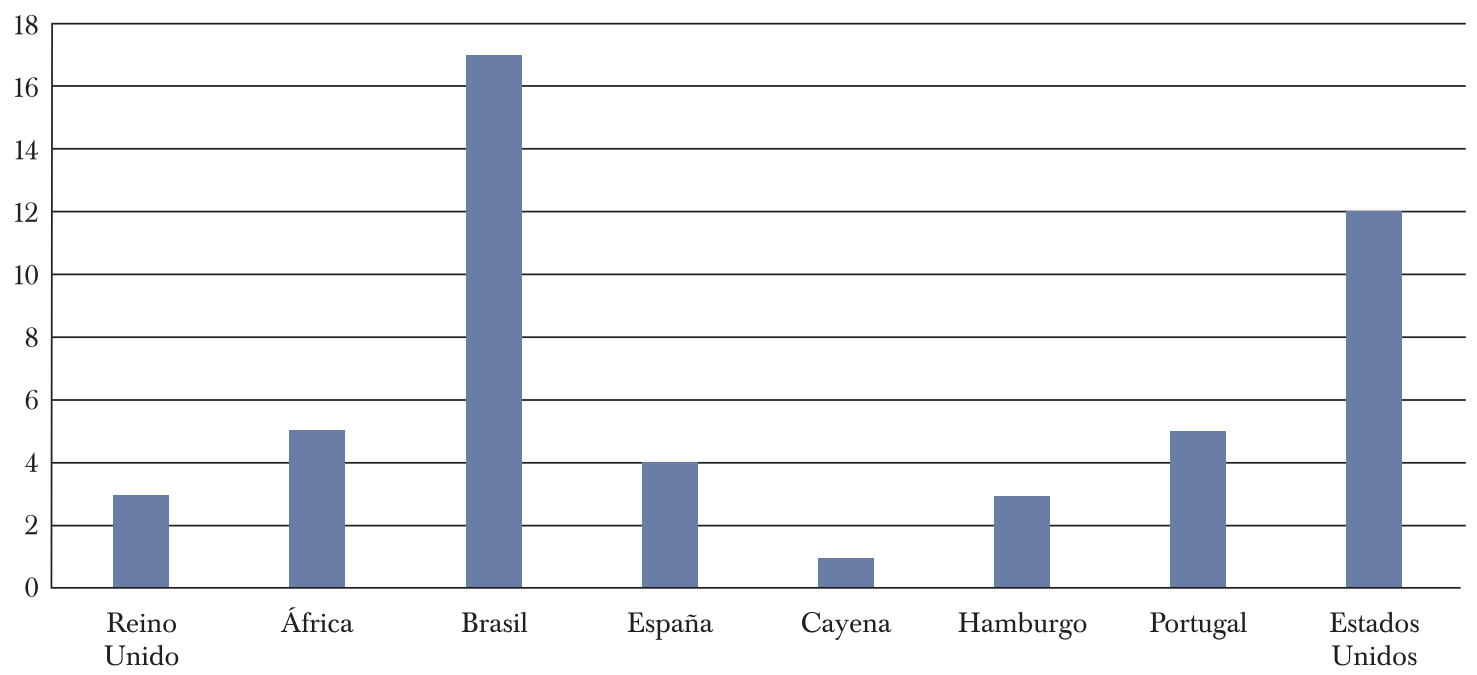

Fuente: Libro maestre de entrada de buques, 1805-1818, 4C, núm. 95. Capitanía del Puerto, Fondo Archivo General Administrativo, AGN-U.

de fuentes tiene dos fundamentos sólidos: en primer lugar nos ofrece un piso mínimo del tráfico mercantil; en segundo, es la única fuente que nos permite triangular la información cuantitativa, proveniente de los archivos británicos, y cualitativa, ofrecida por los actores del proceso (militares y comerciantes ocupantes) (véase cuadro 1 ).

El tráfico portuario de Montevideo sufrió una sustantiva transformación, mediante un ingreso masivo de buques británicos, incluso superior al de los navíos de neutrales, provenientes de puertos de todo el mundo. No obstante, teniendo en cuenta que desde el Reino Unido partieron, entre 1806 y 1807, unos 88 buques mercantes, pareciera que los datos subrepresentan este total, puesto que confirman el ingreso de sólo 67 navíos británicos. Ello puede obedecer a diversos motivos, no necesariamente excluyentes entre sí. En primer lugar, y teniendo en cuenta las ya mencionadas características de la fuente, es posible que La Estrella del Sur no haya publicado el tráfico marítimo completo. En segundo, es posible que un buque mercante haya llegado efectivamente al Río de la Plata pero que no haya ingresado al puerto, ni haya descargado sus mercancías. Por un lado, esta posibilidad se fundamenta en los numerosos testimonios que señalan el pequeño tamaño del mercado montevideano y su rápido abarrotamiento; por otro, la decisión que tomaron una importante cantidad de comerciantes ingleses ante la situación de esperar a que las armas británicas produjeran la caída de Buenos Aires, manteniendo sus mercancías en los buques. El testimonio del comerciante español Martín de Álzaga, esgrimido desde Montevideo, en marzo de 1807, sostiene esta posibilidad: "Antes contaban conquistar esa Capital (Buenos Aires, n. del a.) [...] pues hasta

(con un valor total de 24000000 de pesos) que no habían sido incluidas por los informadores holandeses en las Gazette que replicaban en sus páginas el movimiento de navíos del puerto de Cádiz, las que fueron utilizadas por Morineau (1985). En nuestro caso, lamentablemente, no podemos apelar a los registros de navíos como fuente de control de los datos vertidos en La Estrella del Sur. Una mayor descripción del debate y sus consecuencias, véase Schlez (2014, 2017). 


\section{CUADRO 1. BUQUES INGRESADOS Y SALIDOS DE MONTEVIDEO DURANTE LA OCUPACIÓN BRITÁNICA (4 DE FEBRERO-23 DE JUNIO DE 1807)}

\begin{tabular}{llrc}
\hline Buques & Pabellón & Cantidad & Total \\
\hline \multirow{2}{*}{ Ingresados } & Británicos & 67 & \multirow{2}{*}{109} \\
& Extranjeros & 42 & \\
\multirow{2}{*}{ Salidos } & Británicos & 32 & 69 \\
& Extranjeros & 37 & \\
\hline
\end{tabular}

Fuente: Southern Star/La Estrella del Sur (1807).

los comerciantes no querían descargar para llevar a esa sus cargamentos [...] Ya son 70 las embarcaciones mercantes, y todas de mucho valor, sin que puedan vender aquí sino muy pequeñas partidas que no les dan para los gastos de los buques" 30

Asimismo, sabemos que, en junio de 1807 , cuando se ultimaban los preparativos para la invasión de Buenos Aires, una flota de 30 buques mercantes, que no habían descargado en Montevideo, aguardaban la posesión de la capital del virreinato, tal como se desprende del testimonio del brigadier general Craufurd:

Cada preparación se estaba realizando para continuar con toda la expedición contra Buenos Aires [...] El puerto de Montevideo estaba literalmente lleno de barcos: tenía la apariencia de un bosque de invierno. Más de una treintena de embarcaciones eran comerciantes, que se encontraban allí hasta que nuestra posesión de Buenos Aires les permitiera proceder a ese mercado, ya que era imposible disponer de sus cargamentos en este lugar (An authentic narrative, 1808, pp. 115-116) ${ }^{31}$

Tras la derrota de la invasión a Buenos Aires, La Estrella del Sur (11 de julio de 1807) publicó su último número, anunciando que "una cesación de hostilidades entre las fuerzas Bretánicas (sic) y Españolas se ha convenido en este Río de la Plata" 32 Por lo que estos 30 buques, que vieron frustrados sus intentos de descargar sus mercancías en Buenos Aires debido a la derrota militar británica, se vieron obligados a liquidar sus productos en Montevideo, gracias a que Whitelocke logró obtener, en su capitulación, un plazo de dos meses para que las fuerzas invasoras abandonasen la Banda Oriental.

Es decir que la diferencia entre el total de buques que aparecen salidos de Gran Bretaña (un mínimo de 88, según las fuentes británicas) y los efectivamente ingresados en Montevideo (67, según The Southern Star) podría obedecer a que una cierta cantidad (unos 30, como planteó Craufurd) habría esperado avanzar directamente sobre Buenos Aires; pero después del fracaso militar inglés, habría descargado en Montevideo, durante el periodo que va desde la salida del último número de The Southern Star, el 11 de julio, y "la mañana del día 9 de septiembre de 1807" ${ }^{33}$ cuando

${ }^{30}$ Carta de Martín de Álzaga remitida a Buenos Aires (29 de marzo de 1807), Montevideo, Papers of the Government of Buenos Ayres, English Invasions, British Library.

${ }^{31}$ Original en inglés, traducción propia.

${ }^{32}$ Extra (11 de julio de 1807). The Southern Star.

${ }^{33}$ Libro maestre de entrada de buques, 1805-1818, 4C, núm. 95. Capitanía del Puerto, Fondo Archivo General Administrativo, AGN-U. 
los británicos finalmente desalojaron Montevideo. En este punto ciego, de dos meses de duración, para el cual no poseemos datos sobre el tráfico marítimo (con excepción de los informes cotidianos de los comandantes militares sobre la recolección de impuestos y las ventas en Montevideo) habría ingresado un número importante de buques, que nuestro trabajo no logra cuantificar, más allá de las especulaciones planteadas ${ }^{34}$

Estos informes prueban, junto con el testimonio de los comerciantes españoles, que la derrota militar británica desató dos meses febriles en términos comerciales, debido a que los mercaderes ingleses, enterados de que ya no podrían acceder directamente a Buenos Aires, liquidaron sus mercancías en Montevideo, en una etapa que la historiografía denominó como de liquidación o baratillo ${ }^{35}$ En palabras del Consulado de Buenos Aires, el ejército invasor aspiraba "a nuevos contratos que sólo llevan el fin del monopolio", acusación que muestra la gravedad del hecho que se estaba desarrollando luego de la victoria española 36

Por otro lado, volviendo a los datos ofrecidos por el cuadro 1, el que aparezca una menor cantidad de buques salidos de puerto en relación con los ingresados, obedece al mismo elemento histórico y político: la derrota militar y la obligación de evacuar Montevideo, en septiembre de 1807, no sólo implicó la falta de registro sistemático de todo movimiento mercantil, sino también el abandono masivo de la región, por parte de los buques mercantes y la flota militar. En ese sentido, el multitudinario abandono de Montevideo implicó la salida de dos centenares de navíos.

Teniendo en cuenta estos elementos, consideramos que los datos ofrecidos por el Southern Star representan un mínimo que, de acuerdo con las fuentes cualitativas, fue ampliamente sobrepasado, y aunque su representatividad cuantitativa puede ser cuestionada, nos ofrecen una serie de datos que ilumina particularmente el movimiento comercial durante la ocupación británica de Montevideo (véanse gráficas 6 y 7 ).

Las gráficas 6 y 7 muestran un cambio fundamental respecto del quinquenio previo a la invasión, con el establecimiento de un comercio directo, con cierta regularidad, y cuantitativamente muy superior a cualquier precedente, entre el Río de la Plata y los puertos británicos. Asimismo, se observa una permanencia en la importancia de los puertos del Brasil y Estados Unidos, aunque se hace evidente un retroceso del vínculo con Alemania, explicado, probablemente, por los impuestos que los británicos exigieron a las principales importaciones desde allí provenientes, que virtualmente imposibilitaron la continuidad de dicho tráfico ${ }^{37}$

\footnotetext{
${ }^{34}$ General Whitelocke a Lord Castlereagh (10 de septiembre de 1807), HMS Medusa, fuera de Montevideo, War Office, $1 / 162$, TNA.

${ }^{35}$ Bentancur (1998) asegura que "los dos últimos meses fueron a su vez de beneficioso 'baratillo", por el plazo otorgado al invasor para desalojar Montevideo. Para ello cita a José Batlle y Carreó afirmando que "el negocio ventajoso [...] proporcionó más de 100 por 100 a los que pudieron emplear". Asimismo, señala que las transacciones se vieron beneficiadas debido a que el gobernador Elío quebró la prohibición virreinal de comerciar con el enemigo, justificando su autorización en la "miseria, que las circunstancias de una guerra ruinosa, había reducido a la mayor parte del vecindario" y "por el corto término que falta para la marcha de los enemigos", permitiendo que los británicos adquirieran productos del país “a plata y no a cambio de géneros" (Bentancur, 1998, pp. 16 y 40). Para ampliar sobre este tema y periodo, véase Schlez (2012).

${ }^{36}$ Sala IX, Cabildo de Buenos Aires, Archivos, 1807, mayo-agosto, 19-5-7, en AGN-A.

${ }^{37} \mathrm{El} 15$ de septiembre de 1806, el Board of Trade (Cámara de Comercio), en Londres, decidió que se impondría $20 \%$ de impuesto sobre todo el lino alemán exportado a Buenos Aires para beneficiar a los fabricantes escoceses e irlandeses, una medida que el Times consideró "igual a una prohibición”. Los resultados de sus deliberaciones se enviaron a Buenos Aires para "la guía de ustedes [...] encomendados al gobierno de esa colonia", The Times (16 de septiembre de 1806). Recuperado de http://www.thetimes.co.uk/archive/ Aunque no hemos encontrado referencias a este impuesto en el Río de la Plata, es probable que su aplicación explique los escasos vínculos con puertos alemanes.
} 


\section{GRÁFICA 6. PUERTO DE ORIGEN DE BUQUES ENTRADOS A MONTEVIDEO (4 DE FEBRERO-23 DE JUNIO DE 1807)}

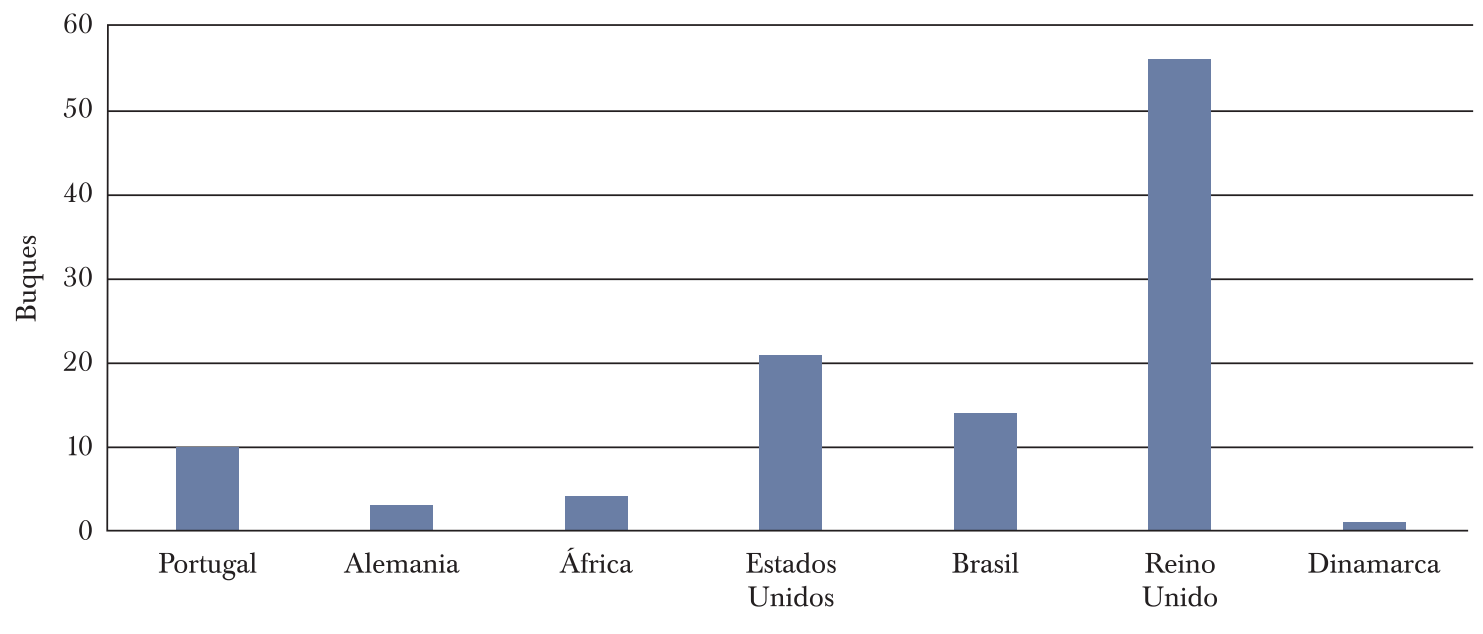

País del puerto de origen

Fuente: The Southern Star/La Estrella del Sur (1807).

Finalmente, junto con el establecimiento del comercio directo con Gran Bretaña y la completa apertura del puerto a todas las naciones, la ocupación británica produjo una interrupción del vínculo regular entre el virreinato del Río de la Plata y la metrópoli española. En este sentido, llama la atención que los buques que partieron del Río de la Plata se hayan dirigido a tres espacios políticos, el Reino Unido, Brasil y Estados Unidos, aunque amplios en términos geográficos, vinculados entre sí política e históricamente. Pasemos, entonces, a evaluar la cuestión de los retornos, una vez que los navíos abandonaban el Río de la Plata.

\section{LA CUESTIÓN DE LOS RETORNOS}

Los libros de importación de Gran Bretaña (que no incluyen Irlanda) confirman el regreso de tan sólo 29 buques provenientes del Río de la Plata, en 1807 Asimismo, es un dato confirmado por la correspondencia que una serie de navíos mercantes regresó a Londres, puesto que funcionaron como correo de la comunicación entre los generales en Montevideo y el gobierno de su majestad 39 No obstante, cuestiones metodológicas e históricas nos impiden un análisis fiable de los retornos de buques desde el Río de la Plata a los puertos del Reino Unido. Veamos estos aspectos que atañen a las fuentes existentes y a los mecanismos comerciales que la derrota de la invasión puso en marcha.

En primer lugar, ya nos hemos referido a que la victoria española impuso a los comerciantes británicos la necesidad de liquidar sus mercancías. Esto implicó venderla a precios bajos, por un lado, y entregarla en consignación, ofreciendo la posibilidad de pagarla en plazos; por el otro,

\footnotetext{
${ }^{38}$ States of Navigation, Commerce and Revenue, 1807, CUST 17/29, TNA.

39 “Señor, al descubrir que el barco mercante por el cual le escribí hace unos días, aún no ha navegado, ahora tengo la satisfacción de informarle que ayer recibí una carta del general de brigada Craufurd, informando su llegada a la entrada del Río de la Plata”, J. W. Whitelocke a William Wyndham (31 de mayo de 1807), Montevideo, War Office, 1/162, TNA (original en inglés, traducción propia).
} 


\section{GRÁFICA 7. PUERTO DE DESTINO DE BUQUES SALIDOS DE MONTEVIDEO (4 DE FEBRERO - 23 DE JUNIO DE 1807)}

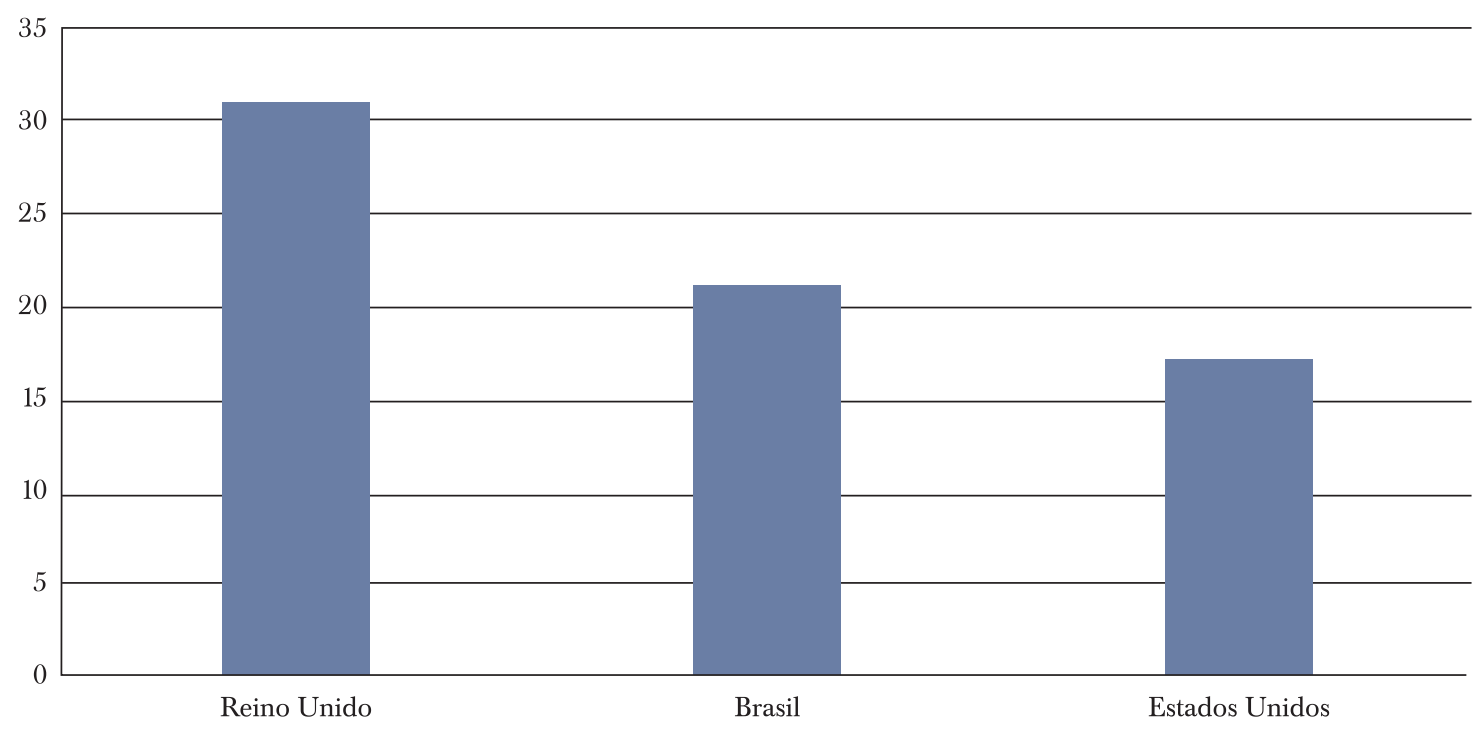

Fuente: The Southern Star/La Estrella del Sur (1807).

ya sea con moneda o con mercancías americanas, fundamentalmente cueros. Existen numerosos testimonios de este tipo de ventas en las fuentes rioplatenses, como se observa en el copiador de cartas de Domino de Ugalde, en el que se asegura que "en esta [Montevideo] están haciendo un negocio loco los de esta y los que han venido de esa [Buenos Aires] ${ }^{40}$ y que "un comerciante inglés que conozco mucho tiempo hace me quería vender por 30 mil pesos de efectos para pagar a los tres meses", en momentos en que los invasores "están preparando para evacuar esta plaza y están vendiendo todas las cosas más baratas", ${ }^{41}$ De allí que una parte (difícil de mensurar) de los retornos (en metales, dinero o mercancías) se concretaron a futuro, y no cuando los británicos desalojaron de Montevideo. En este sentido, Crouzet (1958) señaló que ellos se demoraron por años, determinando la imposibilidad de cerrar la operación en el corto plazo. Por este motivo, el análisis clásico de balanza comercial no puede concretarse en este caso, y sólo un estudio de caso podría adentrarse en los montos, tiempos y mecanismos específicos del comercio atlántico que motorizó la invasión.

En segundo lugar, los libros de aduana británicos parecen esconder la cantidad de buques que regresaron desde el Río de la Plata. En el caso de Irlanda, porque directamente no se presentan datos de navegación. En el caso de Inglaterra y Escocia, hay un doble problema: $a$ ) aunque aparecen importaciones rioplatenses en 1806, no se registra ningún buque proveniente desde Buenos Aires o Montevideo; $b$ ) en 1807, cuando debería registrarse más de un centenar de buques regresando de la invasión, sólo aparecen 29 navíos provenientes de Buenos Aires y Montevideo (22 británicos

${ }^{40}$ Domingo de Ugalde a Diego de Agüero, Montevideo (25 de agosto de 1807), Particulares, caja 1, AGN-U.

${ }^{41}$ Domingo de Ugalde a Diego de Agüero, Montevideo (26 de agosto de 1807), Particulares, caja 1, AGN-U. 
y siete extranjeros). ¿Qué ocurrió con el resto de las naves si, como muestran las salidas desde Montevideo (y hemos resumido en la gráfica 7), una enorme cantidad de navíos partió hacia el Reino Unido?

Advirtiendo sobre la posibilidad de un simple error o falta de sistematización, también existe la posibilidad de que esas importaciones rioplatenses hayan llegado escondidas a Gran Bretaña desde otras regiones del imperio británico. Una vez más, puesto que las fuentes españolas no registraron este movimiento, debemos apelar a la información publicada por The Southern Star.

Su análisis nos permite observar que los retornos son menores porque, sencillamente, los buques cargados en el Río de la Plata no regresaron a Gran Bretaña, sino que se dirigieron a otros puertos del imperio. Como señala un edicto de consejo (Order in Council) del 11 de febrero de 1807, el gobierno de su majestad autorizó que los buques que se dirigieron al Río de la Plata pudiesen regresar a cualquier otro puerto:

comandantes de navíos de guerra y corsarios, "Mando y ordeno que todos los buques Británicos que van a salir de cualquier Puerto de nuestro Reyno para Buenos-Ayres y el Río de la Plata tengan permiso de proceder sin interrupción a cualquier puerto de la isla de Santo Domingo que no esté bajo el dominio de la Francia o España: Que vendan sus cargamentos allí o los lleven a algún otro Puerto de nuestro Reyno Unido; o que transporten sus cargamentos a bordo de buques neutrales y los manden a alguna Colonia Enemiga para venderlos y que traigan sus productos a bordo de dichos buques neutrales a cualquier puerto de nuestro Reino Unido" ${ }^{42}$

De acuerdo con esta orden, los comerciantes británicos estaban autorizados a enviar sus mercancías a una enorme cantidad de puertos en todo el mundo, incluso a "colonias enemigas", tanto en buques británicos como neutrales, para luego, desde allí, retornar a Gran Bretaña. Frente a este enorme grado de dispersión, las informaciones vertidas sobre los navíos salidos de Montevideo en The Southern Star nos permiten especificar los puertos de destino, lo que prueba, en qué medida el edicto señalado fue utilizado por los capitanes de los navíos para moverse al interior del imperio británico, tal como hemos sintetizado en la gráfica 8 .

Como podemos ver, luego de las invasiones inglesas, sólo una minoritaria cantidad de buques regresó a Gran Bretaña (nueve navíos a Londres), mientras que otros lo hicieron a islas menores, tales como Jersey, Guernsey y Wight. Asimismo, la segunda gran ruta tuvo como destino a América Central, particularmente a las Indias Occidentales británicas (Jamaica y Trinidad) y a las islas conquistadas (Surinam y Demerara), siguiendo la clasificación de los libros de comercio exterior británicos ${ }^{43}$ Por su parte, también existieron dos rutas alternativas más: la del Cabo de Buena Esperanza, que incluía a la isla de Santa Elena (a mitad de camino entre el Río de la Plata y Sudáfrica), y aquella que tuvo como destino la actual Canadá, en América del Norte, específicamente Halifax (Nueva Escocia), Weymouth y Terranova ${ }_{44}^{44}$ Finalmente, aunque minoritarios

\footnotetext{
${ }^{42}$ Edicto de Consejo (Order in Council) (11 de febrero de 1807), en The Southern Star, 23 de mayo de 1807, núm. 1, p. 2 .

${ }^{43}$ Las Conquered Islands incluían a Demerara, Santa Lucía, Surinam, Tobago y Curazao. cust, 17/29, 1807. TNA.

${ }^{44}$ Puesto que el periódico consigna el nombre de la ciudad, sin aclaraciones mayores, algunas presentan la dificultad de conocer su destino efectivo, como el caso de Weymouth, en el que no podemos confirmar si se trata de Gran Bretaña o del puerto situado en América del Norte, en la actual Canadá.
} 


\section{GRÁFICA 8. PUERTOS DE DESTINO BRITÁNICOS DE BUQUES SALIDOS DE MONTEVIDEO (4 DE FEBRERO - 23 DE JUNIO DE 1807)}

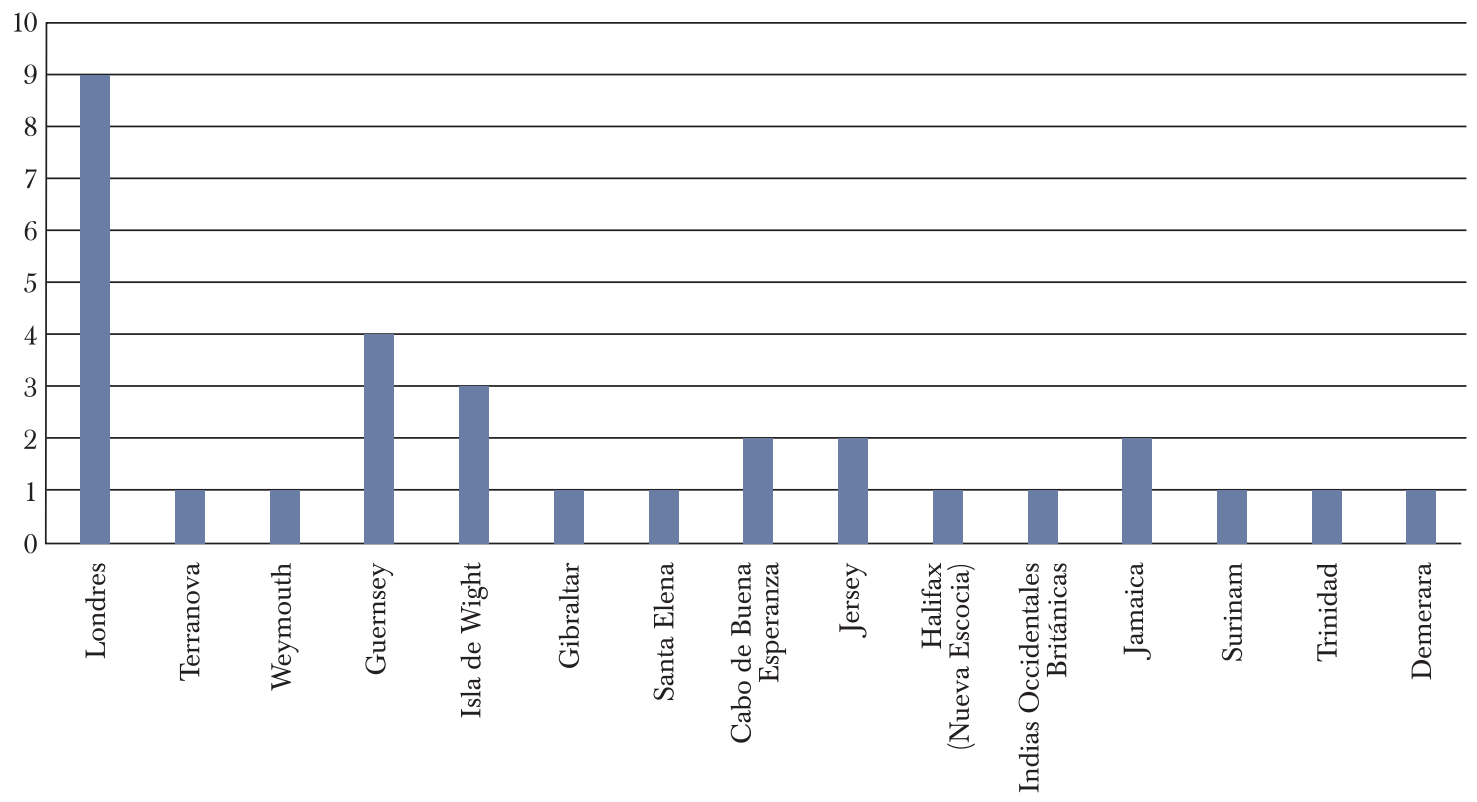

Fuente: The Southern Star/La Estrella del Sur (1807).

Nota: El buque que señaló como destino Gibraltar, en realidad partió hacia España.

en términos de porcentajes, es pertinente señalar que hubo navíos ingleses que partieron desde Montevideo hacia puertos extranjeros, registrándose tres buques destinados a Norfolk (Virginia), uno a Boston (es decir que cuatro viajaron a Estados Unidos), y dos a Río de Janeiro (Brasil).

$\mathrm{Al}$ momento en que la flota británica abandonó el Río de la Plata, a principios de septiembre de 1807, aquella multitud de buques mercantes pudieron haberse dirigido a una gran cantidad de puertos británicos y extranjeros, a los que no podemos acceder por medio de las fuentes que hemos trabajado, y que difícilmente puedan ser dilucidados más allá de las pistas aquí enunciadas, o recurriendo a testimonios cualitativos de los diversos participantes del proceso (comerciantes, soldados, marineros, funcionarios, papeles de gobierno).

En este sentido, resulta una tarea pendiente el confirmar el destino de cada uno de estos buques en los puertos de destino. Como ya probó la historiografía, un sinfín de elementos pueden modificar el destino final de un navío lanzado al Atlántico a principios del siglo xix. Incluso, debemos contar con la posibilidad de que la declaración realizada a las autoridades en el puerto de partida no haya sido cierta. Tal como Silva (2016) probó que ocurrió en el Montevideo ocupado por los ingleses, cuando un grupo de comerciantes españoles lograron engañar a los invasores fraguando tanto la pertenencia de la carga como su destino, en barcos neutrales, declarando que el bergantín estadounidense Minerva se dirigiría a Gibraltar cuando, en realidad, se proponía viajar a Málaga, Cádiz y Barcelona, tal como lo comprueban las cartas remitidas desde Montevideo a España: "El tiempo no permite poder conducir las propiedades españolas con buques de nuestra nación y es 
preciso valerse de ciertos ardides para extraer las propiedades de los que subsisten en nuestra península de Europa, porque si los ingleses llegasen a precaver que subsisten géneros pertenecientes a comerciantes españoles ausentes, los confiscarían..."45

Este hecho, aunque advierte de los problemas de la fuente analizada -los que también caracterizan al resto de la documentación usualmente utilizada para el estudio del comercio colonial-, no invalida los datos obtenidos, aunque su confirmación exija un trabajo que difícilmente pueda realizar un investigador individual, en tanto implica el rastreo de los retornos de las invasiones inglesas en puertos de África, América y Europa.

\section{Conclusiones}

Los datos ofrecidos nos permiten concluir que las invasiones inglesas desataron un tráfico mercantil estimado en un mínimo de 130 naves ( 88 británicas y 42 neutrales) ingresadas al Río de la Plata, la gran mayoría de ellas en Montevideo, debido a la reconquista de Buenos Aires, por parte de los españoles, en 1806, y al rechazo del segundo ataque invasor, en 1807. Aunque es difícil una estimación fundamentada que estipule un número máximo de buques arribados, este no debería haber superado las 200 naves, un número factible bajo dos supuestos: $a$ ) suponiendo que a las 40 naves neutrales, descritas por testimonios orales en octubre de 1806, debiéramos sumarle otras cuarenta y dos, ingresadas a puerto entre abril y junio de 1807, reseñadas en La Estrella del Sur, $\mathrm{y} b$ ) que durante el periodo en el cual no poseemos registros alguno para aproximarnos al tráfico marítimo (de julio a septiembre de 1807) hayan continuado ingresando al puerto regularmente navíos.

Por su parte, aunque partimos de un mínimo de 69 navíos salidos, pues se trató de un tráfico intrínsecamente vinculado a una invasión, planteamos la hipótesis de que la misma cantidad de buques que ingresaron al calor del ataque militar, se marcharon luego de la derrota británica (con la salvedad de una minoría de naves neutrales que podrían haber permanecido en el Río de la Plata). Por lo que el total de embarcaciones entradas y salidas del puerto en el periodo de las invasiones nos ofrece un margen que va desde un mínimo de 199 (130 ingresadas y 69 salidas) a las 400 (suponiendo una entrada máxima de 200 y la salida de la totalidad de los buques).

El primer elemento a señalar es que el número total estimado de buques mercantes que desató la invasión británica no se encuentra alejado de las estimaciones que aparecían en la historiografía (como ya señalamos, rondaban el centenar), aunque podría duplicarlas, según los escenarios que hemos considerado como más probables. Asimismo, lo que aparecía como un movimiento predominantemente británico, se muestra ahora con un importante aporte de naciones neutrales que se sumaron a la invasión con buques y rutas propias. En este sentido, lejos de un movimiento de ida y vuelta entre el Reino Unido y el Río de la Plata, se evidencia que el proceso concentró productos provenientes de mercados diversos, al tiempo que disparó las mercancías rioplatenses hacia puertos que no fueron exclusivos de Gran Bretaña, diversificando sus destinos, incluso, al interior del imperio británico.

Una ponderación más exacta de estos números - para su comparación con otros periodos y regiones de América- exigiría un análisis del tipo, tamaño y tonelaje de los buques ingresados, elementos con los que no contamos aquí. No obstante, una primera comparación concentrada

\footnotetext{
${ }^{45}$ La documentación hallada por Silva (2016) se encuentra en Fondo comercial, AC. B 332, Archivo del Institut Municipal d'Historia de la Ciutat (Barcelona).
} 
exclusivamente en la cantidad de embarcaciones entradas y salidas a puerto coloca al proceso de invasión británica a la misma altura del comercio colonial español en su mejor momento para la totalidad de sus puertos americanos. Por ejemplo, a partir de la información vertida por los estudios clásicos, Pérez Herrero (1992, p. 236) reconstruyó la evolución del número de embarcaciones que comerciaron entre los puertos españoles y América, entre los siglos XVI y XVIII, mostrando que el tráfico alcanzó su pico en la última década del siglo XviII, con un total anual que superó los 600 navíos.

Asimismo, una mirada de largo plazo circunscrita al Río de la Plata nos permite determinar que la invasión británica representó uno de los periodos de mayor tráfico de buques de su historia, sólo comparable con los últimos cinco años del siglo xviII, cuando la entrada y salida de buques sobrepasó los 250 (Silva, 1993; Jumar, 2002; Camarda, 2013). Incluso, el volumen es importante comparado con el movimiento atlántico que inaugurará la Revolución de Mayo, ya liberado completamente del monopolio español; mientras que el volumen es similar al de entradas de buques a Buenos Aires en 1810, que fue de 155 embarcaciones (Silva, 2001, p. 29), por encima del promedio calculado para el puerto de Buenos Aires durante toda esa década: 107 buques entrados por año, incluyendo los de cabotaje (Brown, 2002, p. 145; Hora, 2010, p. 66).

Respecto del pabellón de los buques, el antiguo trabajo de A. Lamas (1892a; 1892b) nos permite observar con mayor detenimiento la aceleración de la crisis del comercio colonial español al calor de las guerras anglo-españolas, y el aumento del comercio entre el Río de la Plata y puertos extranjeros. Sus datos muestran que el tráfico portuario de Montevideo, entre 1803 y el primer semestre de 1806 (previo a la invasión inglesa), estuvo compuesto por $68 \%$ de navíos españoles, $30 \%$ de extranjeros, de los cuales sólo $1 \%$ era británico. Por el contrario, nuestra investigación muestra que, durante las invasiones inglesas, no ingresó al Río de la Plata ningún buque español, y la composición de los navíos ingresados correspondió a $68 \%$ británicos y $32 \%$ neutrales. Es decir que, en perspectiva, la invasión representó la violenta irrupción del comercio directo entre Gran Bretaña y el Río de la Plata, en buques británicos (y, en menor medida, neutrales), provocando una alteración en el curso del proceso histórico que, desde nuestra perspectiva, consideramos el fin de la etapa denominada de comercio con neutrales, inaugurada en 1797 (o en 1783, de acuerdo con los criterios que utilicemos).

Respecto de la composición de los puertos que comercian con el Río de la Plata, la invasión expresa un aumento del peso de los puertos extranjeros, en general, y de Gran Bretaña, en particular. En este sentido, si comparamos el periodo 1779-1806 con el movimiento desatado por la invasión, el cambio es evidente. Los estudios de Camarda (2013) concluyen que los buques ingresados al Río de la Plata, entre 1779 y 1806, provenían en su gran mayoría de España (68\%), aunque con una pequeña presencia de puertos extranjeros, que alcanzaba un mínimo de $14 \%$ (Brasil, $9 \%$; de otros puertos europeos, $2 \%$; de África, $2 \%$; de Estados Unidos, $1 \%$ ). Y como el conjunto de años analizado abarca un periodo relativamente amplio, sucedió un importante incremento del tráfico con puertos extranjeros en los años inmediatamente anteriores a la invasión, y las salidas desde Montevideo, entre 1804 y 1806, nos muestra que $61 \%$ se dirigió a puertos extranjeros, mientras que sólo 39 \% continuó moviéndose entre puertos españoles de América y la península (Silva, 1993).

En este sentido, tal como presentamos en las gráficas 6 y 7, y con la salvedad del buque neutral que finalmente se dirigió a España (y no a Gibraltar), nuestros datos muestran que la totalidad de los vínculos del puerto de Montevideo durante la ocupación británica se establecieron con puertos extranjeros no españoles. Por un lado, la mitad de los buques ingresados $(51 \%)$ y salidos $(45 \%)$ se 
vincularon con puertos británicos. Por el otro, los dos siguientes mercados en importancia fueron el brasileño (13\% de entradas y $30 \%$ de salidas) y el estadounidense (19\% de entradas y $25 \%$ de salidas). Finalmente, más allá de las relaciones minoritarias con la actual Alemania (3\%), es destacable el papel de Portugal (9\%).

Como podemos ver, la invasión representó un ataque militar que le impidió a la metrópoli española vincularse directa y regularmente con la capital de uno de sus virreinatos, al tiempo que le permitió a Gran Bretaña desarrollar, por primera vez, un comercio directo sistemático con una colonia española en América del Sur. Se trató de un cambio abrupto que transformó el comercio exterior rioplatense respecto de sus vínculos comerciales y los buques utilizados para impulsarlo. En este sentido, consideramos que la invasión británica al Río de la Plata representa un momento fundamental del proceso mediante el cual fue destruido el monopolio comercial español en América del Sur, el que fue herido de muerte en la región Río de la Plata entre 1806 y 1807.

Por su parte, al contextualizar el proceso en la historia del vínculo entre el capital mercantil británico y las colonias hispanoamericanas, no consideramos al tráfico mercantil promovido por la invasión como "distorsionador" o "excepcional" (Pearce, 2007, pp. 214-221; 238-250). Por el contrario, a la luz de las pruebas ofrecidas, caracterizamos que el ataque militar inauguró un periodo, delimitado espacial y temporalmente, que representó una fase específica del desarrollo económico y político británico sobre América del Sur, que consideramos puede ser conceptualizada bajo el nombre de comercio directo por invasión. En este sentido, planteamos la hipótesis de que la potencia productiva de Inglaterra, que disputaba abiertamente los mercados europeos y americanos con Francia, Estados Unidos, Portugal y los comerciantes de los territorios de la actual Alemania, encontró en la invasión del Río de la Plata un desarrollo necesario, cualitativa y cuantitativamente diferente a sus etapas previas, y también a las sucesivas, en un proceso que consideramos ajeno a la aleatoriedad planteada por las explicaciones basadas en la invasión como aventura militar individual o como momento excepcional del tráfico mercantil.

Desde nuestra perspectiva, la invasión y ocupación de Buenos Aires y Montevideo expresó el fin de la capacidad española para mantener a los mercados rioplatenses, en alguna medida, sometidos al monopolio, es decir, su falta de poder (político, económico y militar) para sostener su lugar de intermediadora mercantil entre sus colonias americanas y los principales mercados capitalistas de Europa. En este sentido, los diferentes aspectos, no tratados en este artículo, vinculados a este periodo particular de la historia comercial británica y rioplatense (estrategias enfrentadas, sujetos políticos y económicos implicados, volumen, valor y descripción de las mercancías traficadas, resultados comerciales y consecuencias políticas de la invasión) exigen una investigación particular, por lo que serán objeto de trabajos futuros.

\section{LISTA DE REFERENCIAS}

A full and correct report of the trial of Sir Home Popham. (1807). Londres: J. and J. Richardson, C. Chapple.

Acree, W. G. (2011). Everyday reading: print culture and collective identity in the Rio de la Plata, 17801910. Nashville: Vanderbilt University Press.

Albion, R. G. (1963). Movimiento de capital y transporte. El transporte marítimo británico y América Latina, 1806-1914. Buenos Aires: Facultad de Filosofía y Letras. 
An authentic narrative of the proceedings of the expedition under the command of Brigadier-Gen. Craufurd, until its arrival at Monte Video; with an account of the operations against Buenos Aires under the command of Lieut.-Gen. Whitelocke. (1808). Londres: Printed for the author.

Aristizábal, C. (2018). Comerciantes de Buenos Aires y sus redes de comercio con el norte de Alemania, 1796-1810. Boletín del Instituto de Historia Argentina y Americana Dr. Emilio Ravignani, $49,11-46$.

Azcuy, E. (2002). Comercio exterior y comercio de cueros en el virreinato del Río de la Plata. En La otra historia: economía, estado y sociedad en el Río de la Plata colonial (pp. 17-89). Buenos Aires: Imago Mundi.

Bentancur, A. A. (1997). El puerto colonial de Montevideo. Guerras y apertura comercial, tres lustros de crecimiento económico, 1791-1806. Montevideo: Universidad de la República.

Bentancur, A. A. (1998). El puerto colonial de Montevideo. T. II: Los años de la crisis (1807-1814). Montevideo: Facultad de Humanidades y Ciencias de la Educación.

Brown, J. C. (2002). Historia socioeconómica de la Argentina, 1776-1860. Buenos Aires: Instituto Di Tella/Siglo Veintiuno de Argentina.

Camarda, M. (2013). Circulación ultramarina de navíos del Complejo Portuario Rioplatense (17791806). Anuario del Instituto de Historia Argentina, 13, 1-19.

Canter, J. (1938). La imprenta. En R. Levene (ed.), Historia de la nación argentina (vol. 4) (pp. 9-77). Buenos Aires: Universidad de Buenos Aires.

Coria López, L. A. (1992). Tráfico rioplatense en el período hispánico. En Jornadas de Ciencias Económicas (pp. 231-252). Mendoza: Universidad Nacional de Cuyo.

Crouzet, F. (1958). L'economie britannique et le blocus continental (1806-1813). París: Les Presses Universitaires de France.

Eastwick, R. W. (1891). A Master Mariner: Being the Life and Adventures of Captain Robert Eastwick. Londres: T. F. Unwin.

Echeverría, E. (1951). El pensamiento de Mayo. Antecedentes y primeros pasos de la Revolución de Mayo. En Obras Completas (pp. 321-331). Buenos Aires: Ediciones Antonio Zamora.

Fisher, J. R. (2011). The Economic Aspects of Spanish Imperialism in America, 1492-1810. Liverpool: Liverpool University Press. DOI: 10.5949/UPO9781846313011

Frega, A., y Vegh, B. (eds.). (2007). En torno a las “invasiones inglesas": relaciones políticas y culturales con Gran Bretaña a lo largo de dos siglos; [seminario... 16, 17 y 18 de agosto de 2006]. Montevideo: Universidad de la República.

Garavaglia, J. C. (1970). Comercio colonial: expansión y crisis. En Historia integral argentina (vol. 1, pp. 122-140). Buenos Aires: Consejo Empresarial de América Latina.

Garcia, E. S. da V. (1973). Buenos Aires e Cádiz: contribuição ao estudo do comércio livre (17891791)(IV). Revista de História, 47(95), 105-120. DOI:10.11606/issn.2316-9141.rh.1973.13 2038

García-Baquero, A. (1972). Comercio colonial y guerras revolucionarias. La decadencia económica de Cádiz a raíz de la emancipación americana. Sevilla: Escuela de Estudios Hispano-Americanos.

García-Baquero, A. (2003). El comercio colonial en la época del absolutismo ilustrado: problemas y debates. Granada: Universidad de Granada.

Gelman, J. (2010). La revolución y los cambios económicos. En J. Gelman (ed.), Dos siglos después: los caminos de la revolución: textos para el debate (pp. 33-36). Rosario: Prohistoria.

Hora, R. (2010). Historia económica de la Argentina en el siglo XIX (1. ed). Buenos Aires: Siglo XXI Editores. 
Hughes, B. (2013). The British invasion of the River Plate, 1806-7. How the redcoats were humbled and a nation was born. South Yorkshire: Pen \& Sword.

Jumar, F. (2002). Le commerce atlantique au Rio de la Plata, 1680-1778. Villeneuve-d'Ascq: Presses Universitaires du Septentrion.

Jumar, F. (2004). El comercio atlántico de Río de La Plata, 1680-1778. El circuito legal español. Las fuentes utilizadas y su tratamiento. América Latina en la Historia Económica, 11(1), 11. DOI: 10.18232/alhe.v11i1.332

Jumar, F. (2012). La región Río de la Plata y su complejo portuario durante el Antiguo Régimen. En R. Fradkin y J. C. Garavaglia (eds.), De la Conquista a la crisis de 1820 (pp. 124-157). Buenos Aires: UNIPE, Editorial Universitaria.

Kroeber, C. B. (1967). La navegación de los Ríos en la historia argentina, 1794-1860. Buenos Aires: Paidós.

Lamas, D. (1892a). La navegación del Río de la Plata a comienzos del siglo xIx (primera parte). Revista Económica del Río de la Plata, 4, 97-105.

Lamas, D. (1892b). La navegación del Río de la Plata a comienzos del siglo xix (segunda parte). Revista Económica del Río de la Plata, 5, 132-138.

Levene, Ricardo. (1962). Investigaciones acerca de la historia económica del Virreinato del Plata. T. 2. Buenos Aires: Academia Nacional de la Historia.

López, V. F. (1964). Historia de la República Argentina: su origen, su revolución y su desarrollo político hasta 1952 (t. 1). Buenos Aires: Sopena.

Malamud, C. (1985). El comercio de neutrales en el Río de la Plata, 1805-1806 (vol. 4). Luján: Universidad de Luján.

María, I. de. (1957). La imprenta, 1807-1838. En Montevideo antiguo: tradiciones y recuerdos (vol. 2, pp. 61-78). Montevideo: Ministerio de Instrucción Pública y Previsión Social.

Mitre, B. (1940). Historia del Belgrano y de la independencia argentina (tt. 6-8). Buenos Aires: Kraft Ltda.

Morineau, M. (1985). Incroyables gazettes et fabuleux métaux: les retours des trésors américains d'après les gazettes hollandaises (хVIe-XVIIIe siècles). París-Londres: Maison des Sciences de L'homme/Cam bridge University Press.

Moutoukias, Z. (1988). Contrabando y control colonial en el siglo XVII: Buenos Aires, el Atlántico y el espacio peruano. Buenos Aires: Centro Editor de América Latina.

Moutoukias, Z. (1995). El crecimiento en una economía colonial de Antiguo Régimen: reformismo y sector externo en el Río de la Plata (1760-1796). Arquivos do Centro Cultural Calouste Gulbenkian, 34, 771-813.

Nicolau, J. C. (1995). Comercio de ultramar por el puerto de Buenos Aires (1810-1950). Investigaciones y Ensayos, 44, 303-420.

Pearce, A. J. (2007). British trade with Spanish America, 1763-1808. Liverpool: Liverpool University Press.

Pérez Herrero, P. (1992). Comercio y mercados en América Latina colonial. Madrid: MAPFRE.

Ravignani, E. (1952). El volumen del comercio del Río de la Plata a comienzos del Virreinato (1779-1781). Boletín del Instituto de Investigaciones Históricas, 15(9), 25-54.

Roberts, C. (2006). Las invasiones inglesas del Río de la Plata (1806-1807). Buenos Aires: Emecé Editores. 
Schlez, M. M. (2012). “Antes del fin”: los comerciantes monopolistas frente a la crisis y la Revolución (Montevideo, 1789-1820). Tiempos de América: Revista de historia, cultura y territorio, 19, 17-36.

Schlez, M. M. (2013). Los comerciantes de Buenos Aires frente al comercio de neutrales (17961806). Temas Americanistas, 30, 63-86.

Schlez, M. M. (2014). El comercio colonial: balance y propuesta. En M. González Mezquita (ed.), Historia moderna: procesos y representaciones (pp. 375-381). Universidad Nacional de Mar del Plata.

Schlez, M. M. (2016a). El comercio de un monopolista. Volumen, contenido y sentido de la circulación, según un estudio de caso (Río de la Plata, 1770-1820). Anuario de Estudios Americanos, 73(1), 163-198. DOI: 10.3989/aeamer.2016.1.06

Schlez, M. M. (2016b). La medición de la ganancia mercantil en el Río de la Plata colonial: el caso de Diego de Agüero y Compañía (Río de la Plata, 1770-1820). Revista de Indias, 76(268), 751. DOI: $10.3989 /$ revindias.2016.023

Schlez, M. M. (2017). Le commerce atlantique de Buenos Aires à l'ère révolutionnaire (17781830). Bilan historiographique et perspectives de recherche. En D. E. Rojas (ed.), Amérique latine globale: histoire connectée, globale et internationale (pp. 49-96). París: L’Harmattan.

Schlez, M. M. (2018). Un fatal golpe a todos los de mi clase. El combate en torno a la permisión provisoria de comercio con los extranjeros en el Río de la Plata (1809-1810). En J. A. Piquera y J. von Grafenstein (eds.), El pensamiento económico del reformismo criollo. México: Instituto de Investigaciones Dr. José María Luis Mora.

Segreti, C. S. A. (1987). Temas de historia colonial: comercio e injerencia extranjera. Buenos Aires: Academia Nacional de la Historia.

Silva, H. A. (1978). The United States and the River Plate: interrelations and influences between two revolutions. En J. S. Tulchin (ed.), Hemispheric perspectives on the United States papers from the New World Conference. Connecticut: Greenwood Press.

Silva, H. A. (1984). Hamburgo y el Río de la Plata: vinculaciones económicas a fines de la época colonial. Jahrbuch für Geschichte Lateinamerikas, 21(1). DOI: 10.7788/jbla-1984-0111

Silva, H. A. (1990). La españolización de navíos norteamericanos en el Río de la Plata: entre la legalidad y el fraude. Estudios de historia social y económica de América, 6, 65-68.

Silva, H. A. (1993). El comercio entre España y el Río de la Plata (1778-1810). Madrid: Banco de España.

Silva, H. A. (1996). La portuguización y españolización de navíos en las relaciones entre Brasil y el Río de la Plata: finales del siglo xviII y principios del xix. Cuadernos Americanos, 60, 185-198.

Silva, H. A. (2001). El comercio exterior del Río de la Plata hasta 1820. En Academia Nacional de la Historia. Argentina (ed.), Nueva historia de la nación argentina (vol. 6, pp. 13-32). Buenos Aires: Academia Nacional de la Historia/Planeta.

Silva, H. A. (2010). El comercio exterior y la navegación rioplatense en épocas de conflicto. Política y economía. En H. A. Silva (ed.), Historia económica del Cono Sur de America: Argentina, Bolivia, Brasil, Chile, Paraguay y Uruguay: la era de las revoluciones y la independencia (pp. 181221). México: Instituto Panamericano de Geografía e Historia.

Silva, H. A. (2013). La guerra de 1796 y la apertura rioplatense al tráfico marítimo internacional. En I. Lobato Franco y J. M. Oliva Melgar (eds.), El sistema comercial español en la economía mundial (siglos XVII-XVIII) (pp. 303-323). Huelva: Universidad de Huelva. 
Silva, H. A. (2016). El Río de la Plata colonial. Base Sud-Atlántica para las rutas del cacao. En J. Arroyo, A. J. Rodríguez, y J. A. Martínez (eds.), Viaje del mundo: ensayos en honor a Carlos Martínez Shaw (pp. 175-196). Valladolid: UNED.

Street, J. (1967). Gran Bretaña y la independencia del Río de la Plata. Buenos Aires: Paidós.

Torre, E. (1996). El comercio británico desde Brasil al puerto de Buenos Aires en el contexto revolucionario del Río de Plata. En H. A. Silva (ed.), Navegación y comercio rioplatense (vol. 1, pp. 131-154). Universidad Nacional del Sur: Bahía Blanca.

Torre, E. (1999). Aspectos en torno al comercio marítimo. Buenos Aires-Brasil. 1810-1813. En H. A. Silva (ed.), Navegación y comercio rioplatense (vol. 2, pp. 181-202). Bahía Blanca: Universidad Nacional del Sur.

Villalobos, S. (1962). El comercio extranjero a fines de la dominación española. Journal of InterAmerican Studies, 4(4), 517. DOI: $10.2307 / 165188$

Walker, G. J. (1979). Política española y comercio colonial, 1700-1789. Barcelona: Ariel.

Wedovoy, E. (1955). Estudio preliminar. En Nuevo aspecto del comercio en el Río de la Plata (pp. 7 105). Buenos Aires: Raigal.

Winfield, R. (2008). British warships in the Age of Sail 1793-1817: design, construction, careers and fates. Havertown: Seaforth Publishing. 